\title{
Predicting Selectivity of Uranium vs. Vanadium from First Principles: Complete Molecular Design and Adsorption Modeling
}

Fuel Cycle Research \& Development

\author{
Prepared for \\ U.S. Department of Energy \\ Fuel Cycle Research \& Development \\ A. S. Ivanov, S. Das, \\ V. S. Bryantsev, C. Tsouris \\ Oak Ridge National Laboratory \\ A. P. Ladshaw, S. Yiacoumi \\ Georgia Institute of Technology \\ September 15, 2016 \\ FCRD-2016-M2FT-16OR030201032
}




\section{DISCLAIMER}

This information was prepared as an account of work sponsored by an agency of the U.S. Government. Neither the U.S. Government nor any agency thereof, nor any of their employees, makes any warranty,

expressed or implied, or assumes any legal liability or responsibility for the accuracy, completeness, or usefulness, of any information, apparatus, product, or process disclosed, or represents that its use would not infringe privately owned rights. References herein to any specific commercial product, process, or service by trade name, trade mark, manufacturer, or otherwise, does not necessarily constitute or imply its endorsement, recommendation, or favoring by the U.S. Government or any agency thereof. The views and opinions of authors expressed herein do not necessarily state or reflect those of the U.S. Government or any agency thereof. 
Predicting selectivity of uranium vs. vanadium from first principles

September 15, 2016 


\section{SUMMARY}

Background: Uranium is used as the basic fuel for nuclear power plants, which generate significant amounts of electricity and have life cycle carbon emissions that are as low as renewable energy sources. The extraction of this valuable energy commodity from the ground remains controversial, however, mainly because of environmental and health impacts. Alternatively, seawater offers an enormous uranium resource that may be tapped at minimal environmental cost. Currently, amidoxime polymers are the most widely considered adsorbent materials for large-scale extraction of uranium from seawater, but they are not perfectly selective for uranyl, $\mathrm{UO}_{2}{ }^{2+}$. In particular, the competition between $\mathrm{UO}_{2}{ }^{2+}$ and vanadium $\left(\mathrm{VO}^{2+} / \mathrm{VO}_{2}{ }^{+}\right)$cations poses a significant challenge to the efficient mining of $\mathrm{UO}_{2}{ }^{2+}$. Thus, accelerating progress in the discovery and deployment of advanced materials for the recovery of uranium relies on the design of new ligands with high binding affinity and selectivity for uranium over competing metal ions. A cost-effective route to aid the discovery of new ligands is to apply computational methods to rapidly test attractive candidates and elucidate data-driven guidelines for rational design.

Objectives: One of the key components in achieving rational design of highly selective ligands is the establishment of computational tools capable of assessing ligand selectivity trends. Therefore, the objectives of this study include:

1. Establish first-principles methods, based on computational chemistry techniques, to calculate stability constants for $\mathrm{UO}_{2}{ }^{2+}$ and $\mathrm{VO}^{2+} / \mathrm{VO}_{2}{ }^{+}$complexes.

2. Develop computational protocols to assess the binding strengths and selectivity of ligands that can be present in the actual poly(acrylamidoxime) adsorbents.

3. Develop adsorption models that can use information from first-principles computational methods to predict the adsorption behavior of uranium and vanadium by adsorbents synthesized at ORNL and compare results with experimental data.

Results: In the first part of the study, we present an approach based on quantum chemical calculations that achieves high accuracy in reproducing experimental aqueous stability constants for $\mathrm{UO}_{2}{ }^{2+}$ and $\mathrm{VO}^{2+} / \mathrm{VO}_{2}{ }^{+}$ complexes, providing the essential foundation for prospective screening of existing or even yet unsynthesized ligands with higher selectivity for uranium over vanadium. The developed computational protocols were used to assess the binding strengths and selectivity of aliphatic dicarboxylate ligands that can be present in the actual poly(acrylamidoxime) adsorbents. It was found that simple dicarboxylic functional groups possess low binding affinity and selectivity for uranyl, because their backbones present architectures that are poorly organized for the $\mathrm{UO}_{2}{ }^{2+}$ complexation. In the second part of the study, adsorption models were developed and coupled with the results of the molecular studies in an effort to predict the adsorption of uranium and vanadium by the ORNL AF1 (a copolymer of amidoxime and itaconic acid) fiber adsorbent. These models can account for the effects of ligand surface density, specific surface area, surface charging, and other non-idealities of the adsorbent surface. It was found that by utilizing the reaction schemes and binding strengths proposed by the molecular studies, the adsorption model could accurately predict the uptake of uranium by both the acyclic amidoxime (AO) and cyclic imide dioximate (IDO) ligand in the ORNL laboratory studies, especially in the more neutral $\mathrm{pH}$ ranges ( $\mathrm{pH} 5$ to 9). The model, however, performed less adequately for predicting the uptake of vanadium for the same adsorbent. By exploring the causes behind the discrepancy between the adsorption model and the ORNL laboratory data, we found that the effect of surface charging was suppressing the total vanadium uptake predicted by the model. An investigation of literature revealed that the crystal structures of the 1:2 vanadium/IDO complex involved a sodium ion $\left(\mathrm{Na}^{+}\right)$, which neutralized the charge of the adsorbed species. When this charge neutral species was included in the adsorption model, the predictions of the vanadium capacities were significantly improved across all $\mathrm{pH}$ ranges. This result suggests that, during adsorption, some surface species may closely associate with, or adsorb, counter-ions from solution to neutralize the charge of the adsorbent surface. 
Significance: This study is particularly significant when considering whether to produce an otherwise highly attractive ligand that may be synthetically challenging. If such a ligand is predicted by our calculations to achieve the desired uranium vs. vanadium selectivity, this substantially reduces the risk of taking on such synthetic challenges. Moreover, the elimination of ligands that are unlikely to show a good uranyl binding affinity can release resources to focus on more promising $\mathrm{UO}_{2}{ }^{2+}$ - selective ligands. Furthermore, the results can successfully rationalize the experimentally observed loss in selectivity of amidoxime-based fibers as the number of adsorption/elution cycles increases, leading to the conversion of a significant amount of amidoxime to carboxylates. The obtained data enabled us to propose ligand design principles based on structural preorganization to achieve a dramatic enhancement in carboxylates binding affinity and selectivity toward $\mathrm{UO}_{2}{ }^{2+} v s . \mathrm{VO}^{2+} / \mathrm{VO}_{2}{ }^{+}$. This concept was exemplified through the investigation of the complexes of the $\mathrm{UO}_{2}{ }^{2+}, \mathrm{VO}_{2}{ }^{+}$, and $\mathrm{VO}^{2+}$ ions with the highly preorganized ligand PDA (1,10-phenanthroline-2,9-dicarboxylic acid) by a combination of quantum chemical calculations, along with fluorescence and absorbance techniques. The predictive power of the developed computational protocols was also demonstrated for amidoxime-type ligands, providing greater insights into new design strategies for the development of the next generation of adsorbents with high selectivity toward $\mathrm{UO}_{2}{ }^{2+}$ over $\mathrm{VO}^{2+} / \mathrm{VO}_{2}{ }^{+}$ions. In particular, our results suggest that the IDO functional group is the more preferable configuration for sequestration of uranium from seawater than the acyclic amidoxime (AO). However, at the same time IDO shows stronger binding affinity and higher selectivity for $\mathrm{VO}_{2}{ }^{+}$over $\mathrm{UO}_{2}{ }^{2+}$ and is likely responsible for the higher sorption of vanadium ions in marine tests, while AO does not appear to bind the $\mathrm{VO}_{2}{ }^{+}$ions at all under seawater conditions. Furthermore, as indicated by the simulated speciation diagrams, vanadium forms complexes with cyclic imide dioximate over a large range of $\mathrm{pH}$ values, which may complicate efforts to strip vanadium from the fibers that are being developed to sequester uranium. Thus, selectivity of poly(acrylamidoxime) adsorbents toward $\mathrm{UO}_{2}{ }^{2+} v s . \mathrm{VO}_{2}{ }^{+}$could be improved by minimizing the formation of the cyclic imide dioximate moiety.

Conclusions: Overall, the objectives of this milestone have been successfully met. We have established first-principles methods based on computational chemistry techniques to calculate stability constants for $\mathrm{UO}_{2}{ }^{2+}$ and $\mathrm{VO}^{2+} / \mathrm{VO}_{2}{ }^{+}$complexes. We have developed computational protocols to assess the binding strengths and selectivity of ligands that can be present in the actual poly(acrylamidoxime) adsorbents. Finally, we have developed adsorption models that can use information from first-principles computational methods to predict the adsorption behavior of uranium and vanadium by adsorbents synthesized at ORNL and compared results with experimental data. The culmination of molecular modeling studies and adsorption modeling techniques has shown significant promise with regards to ligand design and adsorbent performance prediction. We have demonstrated that the complexation reactions and binding strengths developed through molecular studies can yield the necessary parameters to predict the performance of a particular adsorbent when the appropriate structural parameters are also known (i.e., ligand surface density, specific surface area, mass, volume, etc.). Through these advancements, we now have a computational pathway to adsorbent fiber design, including the types of ligands to incorporate in the adsorbent and how much ligand should be on the surface versus the total available surface area of the fibers. Models developed here can also be used to predict the influence of environmental parameters such as temperature, $\mathrm{pH}$, salinity, and concentration of competing ions on the uranium uptake performance of specific adsorbents. Thus, extensive deployment of the computational approaches presented in this report is expected to answer complex questions related to the extraction of uranium from seawater, with potentially superior adsorbent materials and performance, with respect to environmental parameters, as an end result. 


\section{CONTENTS}

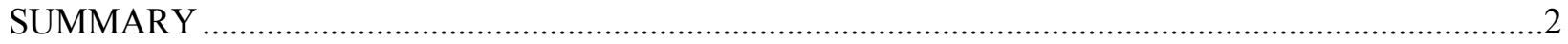

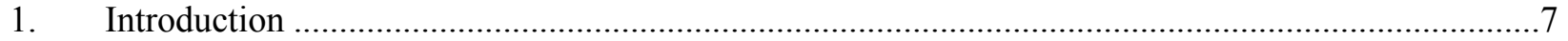

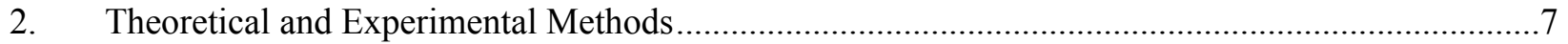

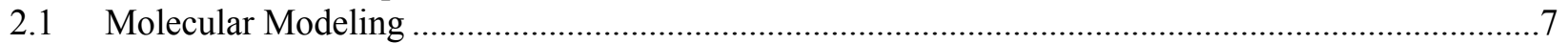

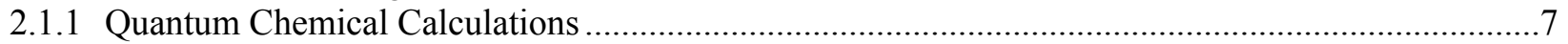

2.1.2 Calculations of Complexation Free Energies and Stability Constants ...........................................8

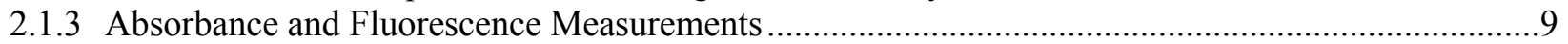

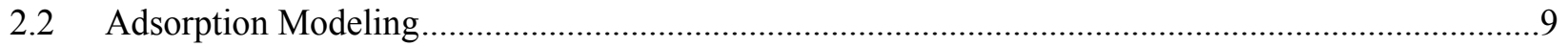

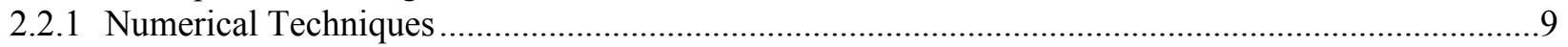

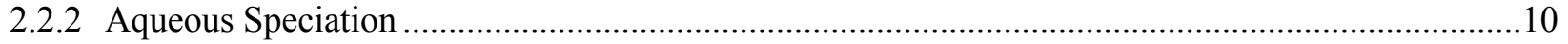

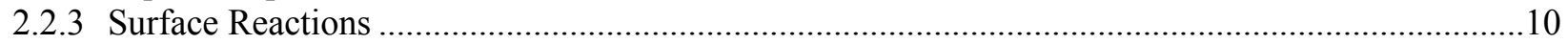

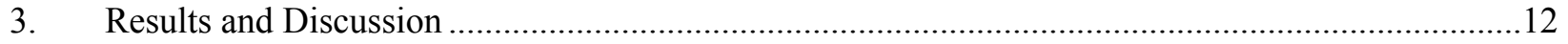

3.1 Predicting Stability Constants using Density Functional Theory ................................................12

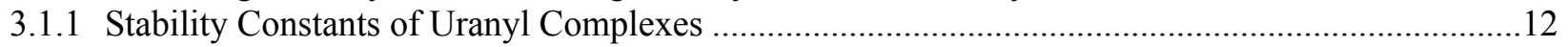

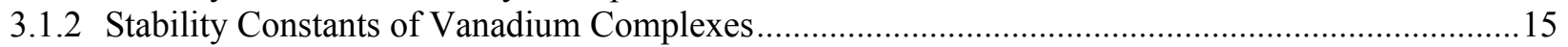

3.1.3 Assessing Ligand Selectivity for Uranium vs. Vanadium ..........................................................18

3.1.4 Role of Open-Chain and Cyclic Amidoxime Functionalities in Selectivity .................................24

3.1.5 Conclusions on Predicting Selectivity for Uranium vs. Vanadium .................................................29

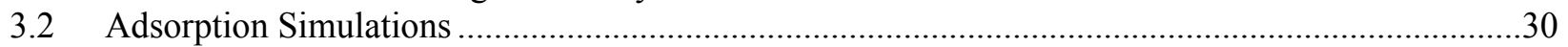

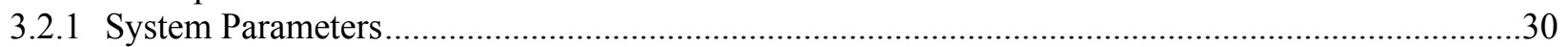

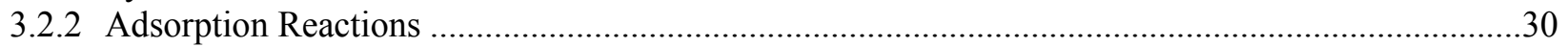

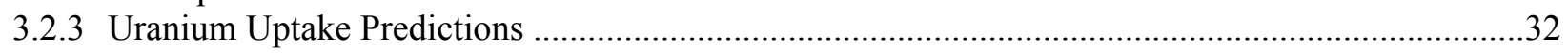

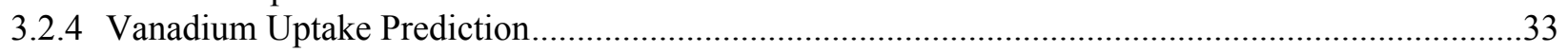

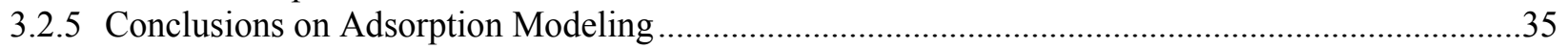

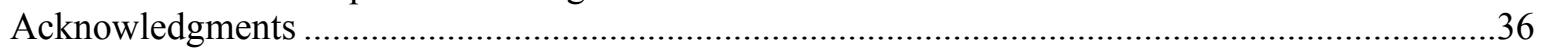

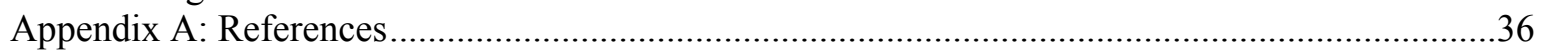




\section{FIGURES}

Figure 1. Thermodynamic cycle used to calculate $\Delta G_{\mathrm{aq}}$

Figure 2. Sets of ligands used to calculate stability constants, $\log K_{l}$ and $\log \beta_{2}$, for corresponding

(a) 1:1 ligand:uranyl complexes and (b) 2:1 ligand:uranyl complexes

Figure 3. Plots of experimental vs. calculated stability constants values in aqueous solution for uranyl complexes with ligands depicted in Figure 2: (a) ligands 1a-22a (1:1 ligand:uranyl correlation) and (b) ligands $1 \mathrm{~b}-7 \mathrm{~b}$ (2:1 ligand:uranyl correlation). Equations for the regression lines: (a) $\log K_{I}^{\text {expt }}=0.560 \times \log K_{I}^{\text {calc }}$, with $\mathrm{R}^{2}=0.938$; (b) $\log K_{I}^{\text {expt }}=0.639 \times$ $\log K_{I}^{\text {calc }}-7.484$, with $\mathrm{R}^{2}=0.985$

Figure 4. Sets of negative oxygen donor ligands used to calculate stability constants, $\log K_{l}$, values for corresponding (a) oxovanadium (IV) and (b) dioxovanadium (V) complexes

Figure 5. Plots of experimental vs. calculated $\log K_{l}$ values in aqueous solution for corresponding (a) oxovanadium (IV) and (b) dioxovanadium (V) complexes with oxygen donor ligands. Equations for the regression lines: (a) $\log K_{l}^{\text {expt }}=0.272 \times \log K_{l}^{\text {calc }}$, with $\mathrm{R}^{2}=0.953$; (b) $\log K_{l}^{\text {expt }}=0.390 \times \log K_{l}^{\text {calc }}-1.583$, with $\mathrm{R}^{2}=0.938$

Figure 6. Histograms showing comparison of experimental (green) and predicted (red) $\log K_{l}$ values for A) $\left.\mathrm{VO}^{2+}, \mathrm{B}\right) \mathrm{VO}_{2}{ }^{+}$, and C) $\mathrm{UO}_{2}{ }^{2+}$ complexes with identical ligands

Figure 7. Comparison of theoretically predicted $\log K_{l}$ values for $\mathrm{UO}_{2}^{2+}$ (red), $\mathrm{VO}_{2}^{+}$(turquoise), and $\mathrm{VO}^{2+}$ (dark blue) complexes with dicarboxylate ligands: I) oxalate, II) malonate, III) succinate, IV) glutarate, V) itaconate (2-methylenesuccinate), VI) 2,2-dimethylsuccinate ......20

Figure 8. PDA (1,10-phenanthroline-2,9-dicarboxylic acid)

Figure 9. Top and side views of the fully optimized geometries (M06/SSC/6-311++G(d,p)) of aqueous 1:1 (a) $\mathrm{UO}_{2}{ }^{2+} / \mathrm{PDA}$, (b) $\mathrm{VO}_{2}{ }^{+} / \mathrm{PDA}$, and (c) $\mathrm{VO}^{2+} / \mathrm{PDA}$ complexes. Color legend: $\mathrm{O}$, red; $\mathrm{N}$, navy blue; $\mathrm{C}$, grey; $\mathrm{H}$, white; $\mathrm{V}(\mathrm{V})$, turquoise; $\mathrm{V}(\mathrm{IV})$, blue; $\mathrm{U}$, orange ..

Figure 10. Schematic depiction of a small subsection of the poly(acrylamidoxime) fiber

Figure 11. (a) Acyclic acetamidoximate $\left(\mathrm{AO}^{-}\right)$and (b) cyclic glutarimidedioximate (IDO ${ }^{2-}$ ) ligands

Figure 12. Species distribution diagrams for (a) $0.0015 \mathrm{M}$ (top) and $0.1 \mathrm{M}$ (bottom) of $\mathrm{AO}^{-}$and (b) $0.0015 \mathrm{M}$ (top) and $0.1 \mathrm{M}$ (bottom) of IDO $^{2-}$ as a function of $\mathrm{pH}$. Concentration of ions used in simulation: $\mathrm{C}_{\text {uranyl }}=1.4 \times 10^{-8} \mathrm{M}, \mathrm{C}_{\text {calcium }}=0.0103 \mathrm{M}, \mathrm{C}_{\text {magnesium }}=0.053 \mathrm{M}$, $\mathrm{C}_{\text {carbonate }}=0.0023 \mathrm{M}$.

Figure 13. Species distribution diagrams for (a) $0.0015 \mathrm{M}$ (top) and $0.1 \mathrm{M}$ (bottom) of $\mathrm{AO}^{-}$and (b) $0.0015 \mathrm{M}$ (top) and $0.1 \mathrm{M}$ (bottom) of IDO $^{2-}$ as a function of $\mathrm{pH}$. Concentration of ions used in simulation: $\mathrm{C}_{\text {vanadium }}=3.6 \times 10^{-8} \mathrm{M}, \mathrm{C}_{\text {carbonate }}=0.0023 \mathrm{M}$.

Figure 14. Uranium adsorption simulation results for the AO ligand compared to the ORNL capacity data (a) and the distribution of each surface species to the total amount of uranium adsorbed (b).

Figure 15. Uranium adsorption simulation results for the IDO ligand compared to the ORNL capacity data (a) and the distribution of each surface species to the total amount of uranium adsorbed (b).

Figure 16. Vanadium adsorption simulation results for the IDO ligand compared to the ORNL capacity data (a) and the distribution of each surface species to the total amount of uranium adsorbed (b).

Figure 17. Vanadium adsorption simulation results for the IDO ligand, with $\mathrm{Na}^{+}$counter-ion charge neutralization, compared to the ORNL capacity data (a) and the distribution of each surface species to the total amount of uranium adsorbed (b). 


\section{TABLES}

Table 1. Comparison of experimental, calculated, and predicted $\log K_{l}$ values

Table 2. Comparison of experimental and predicted $\log \beta_{2}$ values using 1:1 correlation from

Figure 3a .....

Table 3. Comparison of experimental and predicted $\log \beta_{2}$ values using 2:1 correlation from

Figure $3 b$.....

Table 4. Comparison of experimental, calculated, and predicted $\log K_{l}$ values for oxovanadium

(IV) complexes with oxygen donor ligands

Table 5. Comparison of experimental, calculated, and predicted $\log K_{l}$ values for dioxovanadium

(V) complexes with oxygen donor ligands

Table 6. Experimental and theoretically calculated $\log K_{l}$ values for uranyl, dioxovanadium (V), and oxovanadium (IV) complexes with dicarboxylate ligands....

Table 7. Experimental and theoretically calculated $\log K_{l}$ values for uranyl, dioxovanadium(V), and oxovanadium(IV) complexes with the PDA ligand

Table 8. Equilibrium constants for the $\mathrm{UO}_{2}{ }^{2+} / \mathrm{AO}^{-}$and $\mathrm{UO}_{2}{ }^{2+} / \mathrm{IDO}^{2-}$ complexes, all at $25{ }^{\circ} \mathrm{C}$ and zero ionic strength

Table 9. Equilibrium constants for the $\mathrm{VO}_{2}{ }^{+} / \mathrm{AO}^{-}$and $\mathrm{VO}_{2}{ }^{+} / \mathrm{IDO}^{2-}$ complexes, together with literature constants for the $\mathrm{V}(\mathrm{V})$ solution species, all at $25^{\circ} \mathrm{C}$ and zero ionic strength

Table 10. Summary of the system parameters used in the adsorption model. These parameters are based solely on the experimental conditions of the ORNL capacity studies and the AF1 fiber properties.

Table 11. Deprotonation reactions of the IDO and AO ligands with corresponding pKa values at $25^{\circ} \mathrm{C}$ and zero ionic strength.

Table 12. Adsorption reactions and binding constants utilized by the model. These reactions and constants came from the molecular modeling studies and were used to predict uranium and vanadium adsorption. 


\section{INTRODUCTION}

Uranium is the key element for electricity generation through nuclear power. Traditional methods of uranium recovery are usually based on processes that extract uranium ore from the ground, including open pit, underground, and in situ leach mining, all of which cause severe environmental pollution. ${ }^{1}$ Therefore, increasing production of nuclear power will inevitably lead to an even bigger impact on the environment. Moreover, the world's total uranium supply from mines is not sufficient to sustain more than 100 years of power generation at the current consumption rates. ${ }^{2}$ Fortunately, vast amounts of uranium, roughly 1000 times the known reserves of mined uranium, are dissolved in the world's oceans, ${ }^{3}$ largely in the form of $\mathrm{UO}_{2}\left(\mathrm{CO}_{3}\right)_{3}{ }^{4-}$ - uranyl tricarbonate, ${ }^{4}$ and, in contrast to terrestrial resources, may be tapped at minimal environmental cost. However, extraction of uranyl is extremely challenging because it is present at very low concentrations $\left(3.3 \mu \mathrm{g} \mathrm{L}^{-1}\right)$ in seawater. ${ }^{5}$ Although many materials and methods have been developed ${ }^{6-10}$ for the recovery of uranyl from seawater, sorption of $\mathrm{UO}_{2}{ }^{2+}$ by polymers functionalized with amidoximetype ligands has shown the greatest promise. ${ }^{11-13}$

According to a recent report, ${ }^{14}$ the current generation of adsorbents developed at Oak Ridge National Labotatory (ORNL) is capable of capturing up to $3.3 \mathrm{mg} \mathrm{U}$ per g adsorbent after $\sim 60$ days of contact with seawater. However, poly(acrylamidoxime) fibers are not perfectly selective for $\mathrm{UO}_{2}{ }^{2+}$. In particular, the high vanadium uptake ${ }^{15}$ found in real seawater experiments suggests that vanadium ions are competing with uranyl for adsorption to the amidoxime-based sorbent. Indeed, sorption studies ${ }^{16,17}$ have demonstrated that vanadium is strongly adsorbed by poly(acrylamidoxime) fibers, diminishing the effective sites that are available for uranium and thus significantly reducing the sorption capacity and efficiency. Furthermore, the strongly acidic conditions required to elute vanadium cations from the sorbent lower its reusability and eventually damage the sorbent. ${ }^{16,17}$ Therefore, rational design of new chelating agents with enhanced binding affinity and selectivity for uranyl over $\mathrm{VO}^{2+} / \mathrm{VO}_{2}{ }^{+}$ions is expected to help in achieving the overall goal of $\mathrm{UO}_{2}{ }^{2+}$ recovery without sacrificing sorbent durability.

Current experimental efforts toward $\mathrm{UO}_{2}{ }^{2+}$-selective ligand discovery are usually based on the so-called trial-and-error approach and thus require a huge amount of time and resources. Alternatively, computational predictions can provide a more systematic, rapid, inexpensive, and reliable method for the prospective design and screening of superior ligands for selective sequestration of uranium from seawater. While many computational works on uranyl complexation with various ligands have been performed, ${ }^{18-24}$ there have been no theoretical studies regarding quantitative evaluation of ligand selectivity for $\mathrm{UO}_{2}{ }^{2+}$ over competing ions. In the first part of this milestone report, we present a straightforward approach, based on quantum chemical calculations, that is able to prioritize ligands with strong binding affinity and high selectivity toward $\mathrm{UO}_{2}{ }^{2+}$ over $\mathrm{VO}^{2+}$ and $\mathrm{VO}_{2}{ }^{+}$ions. The approach is also utilized to elucidate the main factors influencing the $\mathrm{UO}_{2}{ }^{2+}$ versus $\mathrm{VO}^{2+} / \mathrm{VO}_{2}{ }^{+}$separation ability of poly(acrylamidoxime) sorbent materials.

\section{Theoretical and Experimental Methods}

\subsection{Molecular Modeling}

\subsubsection{Quantum Chemical Calculations}

Electronic structure calculations were performed with the Gaussian 09 D.01 software. ${ }^{25}$ We adopted the

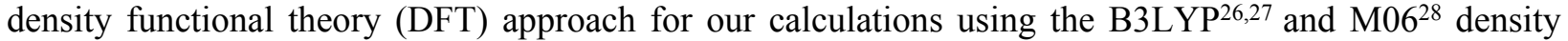
functionals with the standard Stuttgart small-core (SSC) 1997 relativistic effective core potential (RECP), ${ }^{29}$ the associated contracted $[6 \mathrm{~s} / 5 \mathrm{p} / 3 \mathrm{~d} / 1 \mathrm{f}]$ and $[8 \mathrm{~s} / 7 \mathrm{p} / 6 \mathrm{~d} / 4 \mathrm{f}]$ basis sets for vanadium and uranium atoms, respectively, and the $6-311++\mathrm{G}(\mathrm{d}, \mathrm{p})$ basis set for the light atoms. Frequency calculations were performed 
at the $\mathrm{B} 3 \mathrm{LYP} / \mathrm{SSC} / 6-31+\mathrm{G}(\mathrm{d})$ level to ensure that geometries were minima and to compute zero-point energies and thermal corrections using a methodology introduced by Truhlar et al., ${ }^{30}$ which is based on the so-called quasiharmonic approximation - the usual harmonic oscillator approximation, except that vibrational frequencies lower than $30 \mathrm{~cm}^{-1}$ were raised to $30 \mathrm{~cm}^{-1}$ as a way to correct for the well-known breakdown of the harmonic oscillator model for the free energies of low-frequency vibrational modes.

Using the gas-phase geometries, implicit solvent corrections were obtained at $298 \mathrm{~K}$ with the SMD ${ }^{31}$ solvation model as implemented in Gaussian 09 at the B3LYP/SSC/6-31+G(d) level of theory. Since only the first coordination shell was treated explicitly in this study, it was possible to perform a systematic search of low-energy clusters for a given composition. The results are reported using the lowest energy clusters identified at the B3LYP/SSC/6-31+G(d) level for a given stoichiometry and binding motif. In addition, single-point coupled-cluster theory calculations, $\operatorname{CCSD}(\mathrm{T}) /$ aug-cc-pvDZ (the valence electrons on $\mathrm{C}, \mathrm{O}, \mathrm{H}$ and the valence and subvalence electrons $(3 \mathrm{~s}, 3 \mathrm{p})$ on V were correlated), using M06/SSC/6-311++G(d,p) optimized geometries were employed for $\mathrm{V}(\mathrm{V})$ complexes with open-chain amidoxime (AO) and cyclic imide dioxime (IDO) ligands. Molecular dynamics simulations for the $\left[\mathrm{V}(\mathrm{AO})_{3}\right]^{2+}$ complex were performed using VASP - the Vienna ab initio simulation package ${ }^{32-34}$ employing the projector-augmented wave (PAW) potentials ${ }^{35,36}$ and the PBE functional. ${ }^{37,38}$ Simulations using an NVT ensemble at $300 \mathrm{~K}$ with a time step of $1 \mathrm{fs}$ were carried out for $2 \mathrm{ps}$.

\subsubsection{Calculations of Complexation Free Energies and Stability Constants}

Complexation free energies in aqueous solution, $\Delta G_{\text {aq }}$, and stability constants, $\log K_{l}$, were calculated using the thermodynamic cycle shown in Figure 1. According to this cycle, $\Delta G_{\mathrm{aq}}$ is given by:

$$
\Delta G_{\mathrm{aq}}=\Delta G_{\mathrm{g}}^{\mathrm{o}}+\Delta \Delta G_{\text {solv }}^{*}+(n-1) \Delta G^{\mathrm{o} \rightarrow^{*}}+n R T \ln \left(\left[\mathrm{H}_{2} \mathrm{O}\right]\right)
$$

where $\Delta G_{\mathrm{g}}^{\mathrm{o}}$ is the free energy of complexation in the gas phase and $\Delta \Delta \mathrm{G}^{*}{ }_{\text {solv }}$ is the difference in the solvation free energies for a complexation reaction:

$$
\Delta \Delta G_{\text {solv }}^{*}=\Delta G_{\text {solv }}^{*}\left(\left[\mathrm{ML}\left(\mathrm{H}_{2} \mathrm{O}\right)_{m-n}\right]^{\mathrm{x}+\mathrm{y}}\right)+n \Delta G_{\text {solv }}^{*}\left(\mathrm{H}_{2} \mathrm{O}\right)-\Delta G_{\text {solv }}^{*}\left(\left[\mathrm{M}\left(\mathrm{H}_{2} \mathrm{O}\right)_{\mathrm{m}}\right]^{\mathrm{x}}\right)-\Delta G_{\text {solv }}^{*}\left(\mathrm{~L}^{\mathrm{y}}\right)
$$

where $\mathrm{L}^{\mathrm{y}}$ denotes the ligand with a charge of $y$ and $\mathrm{M}$ can be $\mathrm{UO}_{2}{ }^{2+}, \mathrm{VO}^{2+}$, or $\mathrm{VO}_{2}{ }^{+}$.

Standard state correction terms must be introduced to connect $\Delta G_{\mathrm{g}}^{\mathrm{o}}, \Delta \Delta G_{\text {solv }}^{*}$, and $\Delta G_{\mathrm{aq}}$, which are defined using different standard state conventions. The free energy change for the conversion of 1 mol of solute from the gas phase at a standard state of $1 \mathrm{~atm}(24.46 \mathrm{~L} / \mathrm{mol})$ to the aqueous phase at a standard state of 1 $\mathrm{mol} / \mathrm{L}$ at $298.15 \mathrm{~K}$ is given by $\Delta G^{0 \rightarrow *}=1.89 \mathrm{kcal} / \mathrm{mol}$. Likewise, $R T \ln \left(\left[\mathrm{H}_{2} \mathrm{O}\right]\right)=2.38 \mathrm{kcal} / \mathrm{mol}(\mathrm{T}=298.15$ $\mathrm{K})$ is the free energy change for the conversion of $1 \mathrm{~mol}$ of solvent from the aqueous phase at $1 \mathrm{~mol} / \mathrm{L}$ to pure water at a standard state of $55.34 \mathrm{~mol} / \mathrm{L}$. Lastly, the stability constant $\left(\log K_{l}\right)$ value is related to free energy change for the complexation reaction by the following equation:

$$
\log K_{1}=\frac{-\Delta G_{a q}}{2.303 \cdot R T}
$$




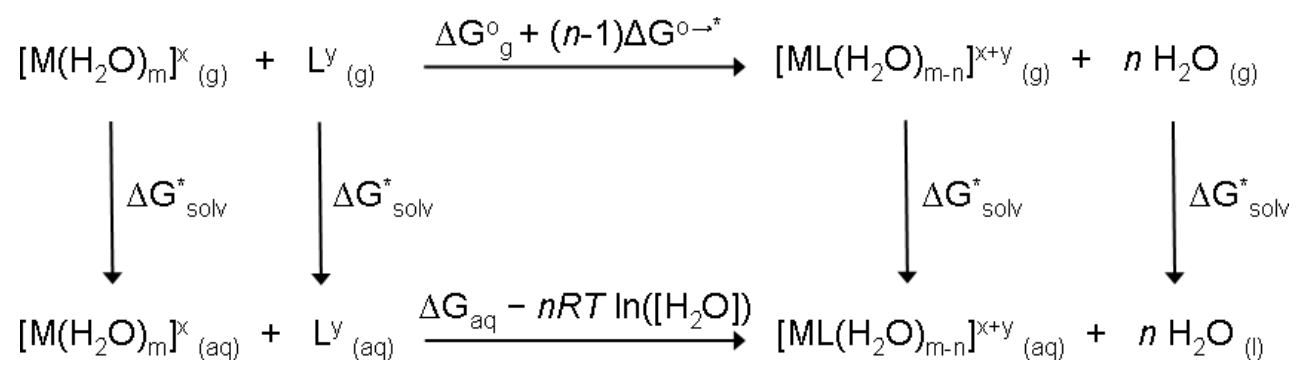

Figure 1. Thermodynamic cycle used to calculate $\Delta G_{\mathrm{aq}}$.

Coefficients ("a" and "b") in linear regression equations $(\mathrm{y}=\mathrm{a}+\mathrm{bx})$ were calculated by the least-squares method. In addition, $p$-values were computed to assess the significance of the coefficients. "a" and "b" were considered to be significant if the $p$-value was less than the significance level $(\alpha=0.05)$. Otherwise, the coefficients were disregarded.

\subsubsection{Absorbance and Fluorescence Measurements}

\section{Materials.}

PDA (1,10-phenanthroline-2,9-dicarboxylic acid) was synthesized by a literature method. ${ }^{39}$ $\mathrm{UO}_{2}\left(\mathrm{NO}_{3}\right)_{2} \cdot 6 \mathrm{H}_{2} \mathrm{O}$ (depleted) was obtained from Fisher and used without further purification. All solutions were prepared in deionized water (Milli-Q, Waters Corp.) of $>18 \mathrm{M} \Omega . \mathrm{cm}^{-1}$ resistivity, plus HPLC grade methanol from Merck.

\section{Absorbance spectra.}

UV-Visible spectra were recorded using a Varian 300 Cary 1E UV-Visible Spectrophotometer controlled by Cary Win UV Scan Application version 02.00(5) software. A VWR sympHony ${ }^{\mathrm{TM}}$ SR60IC pH meter with a VWR sympHony ${ }^{\mathrm{TM}}$ gel epoxy semi-micro combination $\mathrm{pH}$ electrode was used for all $\mathrm{pH}$ readings, which were made in the external titration cell, with $\mathrm{N}_{2}$ bubbled through the cell to exclude $\mathrm{CO}_{2}$. The absorbance spectra of the PDA metal ion solutions were recorded in Milli-Q water. Formation constants were determined using Excel. ${ }^{40}$

\section{Fluorescence Measurements.}

Excitation-emission matrix (EEM) fluorescence properties were determined on a Jobin Yvon SPEX Fluoromax-3 scanning fluorometer equipped with a $150 \mathrm{~W}$ Xe arc lamp and a R928P detector. The instrument was configured to collect the signal in ratio mode with dark offset using $5 \mathrm{~nm}$ band-passes on both the excitation and emission monochromators. The EEMs were created by concatenating emission spectra measured every $5 \mathrm{~nm}$ from 250 to $500 \mathrm{~nm}$ at 51 separate excitation wavelengths. Scans were corrected for instrument configuration using factory supplied correction factors. The fluorescence of the PDA metal ion solutions was recorded in Milli-Q water, with titrations occurring in an external cell with $\mathrm{N}_{2}$ bubbled through the cell to exclude $\mathrm{O}_{2}$.

\subsection{Adsorption Modeling}

\subsubsection{Numerical Techniques}

Adsorption models were developed in $\mathrm{C} / \mathrm{C}++$ to perform speciation and surface reaction calculations that couple together aqueous and adsorbed phase effects of ionic strength, surface charging, competing ions, 
surface steric hindrances, and mass balances. The culmination of all these mechanisms formulates a nonlinear system of equations whose solution would provide the equilibria concentrations of all aqueous and surface species across a range of $\mathrm{pH}$. Parameters necessary in this system of equations includes total mass concentrations, volume of the system, mass of the adsorbent, ligand surface concentration density, and the equilibrium constants for all aqueous and surface reactions of interest.

Solving the non-linear system of equations requires iterative techniques based on the gradients, or derivatives, of each non-linear equation with each non-linear variable. These types of approaches are known as Newton methods, which involve solving a linear sub-system with the Jacobian matrix at all non-linear iterations. In general, computation, storage, and operations on the full Jacobian can be very expensive, but we can improve the efficiency of the approach by making approximations to the actions of a Jacobian matrix on any given vector. This forms the basis of the Jacobian-Free Newton-Krylov (JFNK) method, ${ }^{41}$ which is the technique we employ in our model.

The numerical methods employed to solve the linear sub-system formed from the non-linear problem includes the set of iterative methods commonly referred to as Krylov Subspace methods. ${ }^{42}$ These methods are perfectly suited to our particular problem because they do not require the formulation of the full Jacobian and can be preconditioned to improve convergence. For our application, we primarily use the GMRES algorithm for its generality and flexibility. ${ }^{43}$

\subsubsection{Aqueous Speciation}

The aqueous speciation portion of our model is done in a very standard way and is composed of three parts: (i) mass balance, (ii) electroneutrality, and (iii) equilibrium reactions. Equilibrium reactions, and their corresponding $\log K$ values, dictate the partition between various related ions in the solution, while the mass balances control the total amounts of some given group of species in the system, i.e. uranium, vanadium, etc. The electroneutrality portion of the model is typically used to determine the $\mathrm{pH}$ of the solution based on the concentrations of the various ions. However, if a specific $\mathrm{pH}$ is known, then this portion of the model is replaced with an equality constraint on the $\mathrm{pH}$ variable. ${ }^{44}$

Our approach for modeling aqueous speciation is mathematically the same, or very similar, to various other software packages, such as PHREEQC ${ }^{45}$ and MINEQL $+{ }^{46}$. However, aqueous speciation calculations alone are not adequate enough to predict the metal adsorption on real surfaces. This requires special treatment of the surface/ligand reactions to account for the effects of surface charging, steric hindrance, and/or other non-idealities that might be present. Therefore, coupling the standard aqueous reactions to a mechanistic adsorption surface reaction model is necessary to be able to accurately represent the real system we are interested in modeling.

\subsubsection{Surface Reactions}

\section{Mass Balance Modifications.}

Adsorption is site-specific surface phenomenon in which an adsorbate in some bulk phase (aqueous or gaseous) reacts with an adsorbent surface (or ligand) to produce some new surface (or adsorbed) species. As a result, an amount of the adsorbate is removed from the bulk phase, thus resulting in lower bulk concentration of that species. This requires that the adsorption model provide a modification to the aqueous mass balance equation to account for the loss of mass from the bulk solution. We represent this mathematically below in equation $4:{ }^{47}$ 


$$
C_{T}-\frac{m_{a}}{V} \sum_{j} \delta_{j} q_{j}=\sum_{i} \delta_{i}[i]
$$

where $C_{T}$ is the total concentration of a species group in mol/L (i.e., total uranium), $m_{a}$ is the total mass of adsorbent in the system in $\mathrm{kg}, V$ is the total volume of the system in $\mathrm{L}, \delta_{i}$ is the molar contribution of species $i$ to the total concentration, $q_{j}$ is the adsorption concentration of adsorbed species $j$ in $\mathrm{mol} / \mathrm{kg}$, and $[i]$ is the molar concentration of species $i$ in $\mathrm{mol} / \mathrm{L}$.

\section{Surface Reactions.}

The adsorption reactions themselves look very similar to aqueous reactions with some minor exceptions (Equation 5). On the left hand side of equation 5 are the reactants and on the right hand side are the products. The activity of the adsorbate in solution is represented by the symbol $\{i\}$ and the surface activity of the adsorbed species is $\left\{q_{i}\right\}$. In general, there may be some counter-ions, $\{j\}$, also involved in this reaction, as well as some ion-exchange products, $\{k\}$, formed during adsorption. Stoichiometric coefficients for all aqueous species involved in the reaction are represented by $v$ and $m_{\mathrm{i}}$ represents the molar number of ligands/sites, $[L \phi]$, needed to form the adsorbed species. ${ }^{47}$

$$
v_{i}\{i\}+\sum_{j} v_{j}\{j\}+m_{i}[L \phi] \Leftrightarrow\left\{q_{i}\right\}+\sum_{k} v_{k}\{k\}
$$

A major distinction between adsorption reactions and aqueous reactions is in the treatment of the ligand or surface, which is represented by $[L \phi]$ in equation 5 . This variable represents the concentration of ligands, or surface sites, that are available to bind with the adsorbate. It is represented mathematically in equation 6 below: ${ }^{47}$

$$
[L \phi]=L_{\max }-\sum_{\forall i} m_{i} q_{i}
$$

where $L_{\max }$ is the theoretical maximum ligand concentration of the adsorbent in mol/kg and $q_{i}$ is the actual molar concentration of the $i^{\text {th }}$ adsorbed species bonding with those ligands in $\mathrm{mol} / \mathrm{kg}$. This equation is analogous to a mass balance on the ligand concentration, but represented as the availability of free surface sites.

Similar to aqueous reactions, a surface reaction has an equilibrium constant $\left(K_{i}\right)$ that must be equal to the ratio of products over reactants (Equation 7). This ratio is formed from the activities and stoichiometric constants of all species involved in the surface reaction. However, unlike aqueous reactions, this constant must be adjusted by a correction factor $(\eta)$ to account for the impact of surface charging. ${ }^{47}$

$$
K_{i} \cdot \eta=\frac{\left\{q_{i}\right\} \cdot \prod\{k\}^{v_{k}}}{[M \phi]^{m_{i}} \cdot\{i\}^{v_{i}} \cdot \prod\{j\}^{v_{j}}}
$$

\section{Surface Charging.}

Charging of the adsorbent surface occurs naturally as the ligands bind with ions in solution and form charged surface species. The correction term $(\eta)$ applied to the binding strength for the adsorption reaction is a function of the elementary electric charge constant $\left(e=1.60 \times 10^{-19} \mathrm{C}\right)$, Boltzmann constant $\left(k_{B}=1.38\right.$ 
x $10^{-23} \mathrm{~J} / \mathrm{K}$ ), system temperature ( $T$ in $\mathrm{K}$ ), electric potential of the surface ( $\psi$ in $\mathrm{V}$ ), net aqueous charge exchange $(N)$, and the ionic charges of the aqueous species involved in the reaction $\left(n_{i}\right)$. Equations 8 and 9 below give the mathematical representation of the correction term and net charge exchange term, respectively. ${ }^{47}$

$$
\begin{aligned}
& \eta=\exp \left(-\frac{N e \psi}{k_{B} T}\right) \\
& N=v_{i} n_{i}+\sum_{j} v_{j} n_{j}-\sum_{k} v_{k} n_{k}
\end{aligned}
$$

The electric surface potential $(\psi)$ is related to the surface charge density $(\sigma)$ through the Grahame equation (Equation 10). This model applies the condition of electroneutrality near the adsorbent surface by forcing the total charge of the electric double layer be equal to the negative of the surface charge ${ }^{47}$ Parameters of this model include the gas law constant $(R=8.314 \mathrm{~J} / \mathrm{K} / \mathrm{mol})$, ionic strength of solution $\left(I \mathrm{in} \mathrm{mol} / \mathrm{m}^{3}\right)$, system temperature $(T$ in $\mathrm{K})$, permittivity of water $\left(\varepsilon=7.09 \times 10^{-10} \mathrm{C} / \mathrm{V} / \mathrm{m}\right)$, elementary electric charge constant $(e$ $\left.=1.60 \times 10^{-19} \mathrm{C}\right)$, Boltzmann constant $\left(k_{B}=1.38 \times 10^{-23} \mathrm{~J} / \mathrm{K}\right)$, Faraday constant $\left(F=9.64 \times 10^{4} \mathrm{C} / \mathrm{mol}\right)$, surface concentrations of adsorbed species $\left(q_{i}\right.$ in mol $\left./ \mathrm{kg}\right)$, charges of the surface species $\left(n_{i}\right)$, and specific surface area of the adsorbent $\left(A\right.$ in $\left.\mathrm{m}^{2} / \mathrm{kg}\right)$.

$$
\sqrt{8 \varepsilon R T I} \sinh \left(\frac{e \psi}{2 k_{B} T}\right)=\sigma=-\frac{F}{A} \sum_{i} n_{i} q_{i}
$$

\section{Results and Discussion}

\subsection{Predicting Stability Constants using Density Functional Theory}

Structural and thermodynamic studies, including single crystal X-ray diffractometry, UV/Vis spectroscopy, potentiomentry, and microcalorimetry can be used to assess the competition between $\mathrm{UO}_{2}{ }^{2+}$ and other seawater cations in the sequestration process. ${ }^{48,49}$ For instance, the stability constants, $\log K_{l}$, determined in these studies can help explain and predict the sorption behavior of these cations with amidoxime ligands and thus evaluate the potential of novel, more selective and robust sorbents for uranium extraction. ${ }^{50}$ In an effort to propose new design strategies aimed at improving the ligand selectivity for $\mathrm{UO}_{2}{ }^{2+}$ over $\mathrm{VO}^{2+} / \mathrm{VO}_{2}{ }^{+}$ ions, we have applied density functional theory (DFT) calculations to establish a computational protocol capable of predicting $\log K_{l}$ values for uranyl and vanadium complexes.

\subsubsection{Stability Constants of Uranyl Complexes}

A series of 16 negative oxygen donor and 6 amidoxime ligands (Figure 2a) were selected for study based on several criteria. The availability of accurate aqueous stability constant data for the formation of uranyl complexes was determined by examination of Smith and Martell's compilation of Critical Stability Constants series ${ }^{51}$ Grenthe's treatise on the chemical thermodynamics of uranium, ${ }^{52}$ and recently published data on uranyl complexes with amidoxime-based ligands..$^{53-56}$

Data at $25{ }^{\circ} \mathrm{C}$ were selected to cover as wide a range of $\log K_{l}$ values as possible for rigid ligands with structures capable of exhibiting only one conformation either in the free state or when bound to the uranyl cation. This was done to minimize potential contributions arising from the presence of multiple conformational states, either in the bound or free form of the ligand, and to eliminate uncertainty in the 
selection of initial coordinates for geometry optimizations. In cases where $\log K_{l}$ values were not available at zero ionic strength, they were corrected to zero ionic strength using the Davies equation. ${ }^{57}$ The experimental $\log K_{l}$ values, listed in Table 1 , span a range of nearly 17 orders of magnitude, ranging from a low of 0.0 for nitrate to a high of 16.8 for phthalimidedioxime.

(a)<smiles>CC(=O)O</smiles>

13a

$\mathrm{CO}_{3}{ }^{2-}$

$18 a$<smiles>CC(=O)C=C(C)[O-]</smiles>

2a<smiles>N/C(=N\[O-])c1ccccc1</smiles>

$9 a$<smiles>O=C(O)c1ccccc1C(=O)O</smiles><smiles>[O]C1CCCCC1</smiles><smiles>[O-]c1ccccc1/C=N/O</smiles>

$10 \mathrm{a}$<smiles>O=C(O)c1ccccc1O</smiles>

$15 a$
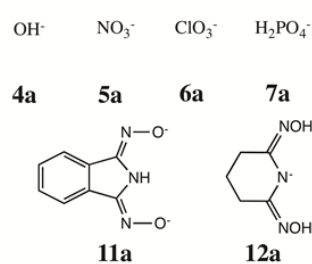

11a

$6 a \quad 7 a$

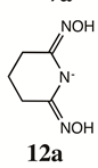

12a

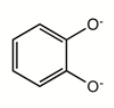

$16 a$

(b)

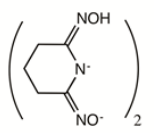

$1 b$

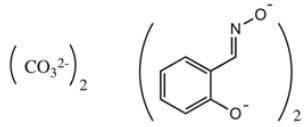

$3 b$

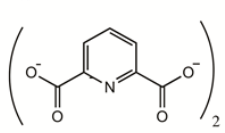

$5 b$

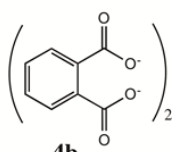

$4 b$

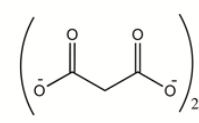

$7 b$

Figure 2. Sets of ligands used to calculate stability constants, $\log K_{l}$ and $\log \beta_{2}$, for corresponding (a) 1:1 ligand:uranyl complexes and (b) 2:1 ligand:uranyl complexes.

Following the approach illustrated in Figure 1, $\Delta G_{\text {aq }}$ values were calculated for the equilibrium shown in eq 11:

$$
\left[\mathrm{UO}_{2}\left(\mathrm{H}_{2} \mathrm{O}\right)_{5}\right]^{2+}+\mathrm{L}^{x-} \rightleftharpoons\left[\mathrm{UO}_{2} \mathrm{~L}\left(\mathrm{H}_{2} \mathrm{O}\right)_{5-\mathrm{n}}\right]^{2-x}+n \mathrm{H}_{2} \mathrm{O}
$$

These calculations require initial atomic coordinates for each species. Given that the geometry of the predominant solvated uranyl ion in aqueous solution, $\left[\mathrm{UO}_{2}\left(\mathrm{H}_{2} \mathrm{O}\right)_{5}\right]^{2+}$, is $\mathrm{known}^{58}$ and the anionic ligands, $\mathrm{L}^{x-}$, have only one populated conformation, a possible ambiguity regarding the geometry of species present in eq 11 occurs only with the $\left[\mathrm{UO}_{2} \mathrm{~L}\left(\mathrm{H}_{2} \mathrm{O}\right)_{5-n}\right]^{2-x}$ complex. There are two issues: (i) whether $\mathrm{L}^{x-}$ interacts in a unidentate or bidentate fashion and (ii) the number of water molecules that are displaced when the ligand coordinates the metal. These issues were addressed computationally and the lowest energy configurations were used in $\Delta G_{\mathrm{aq}}$ calculations.

As can be seen from Table 1, the order of ligand strength is correctly determined. However, the calculated $\log K_{1}$ values are significantly overestimated. These results are consistent with previous studies indicating that accurate computation of absolute complexation free energies for reactions involving multi-charged ions is a difficult task. In addition to deficiencies in the applied density functional theory and the associated basis set, the results of calculations are highly sensitive to the choice of a cluster and solvation model. A part of the problem is that continuum dielectric models are often not adequate when dealing with solutes that have concentrated charge densities with strong local solute-solvent interactions. As a result, electronic structure calculations for ions within the context of pure dielectric continuum models are often prone to make large errors in the hydration free energies. ${ }^{59}$

As follows from Figure 3a, the "raw" $\log K_{1}$ values calculated directly from eq 11 show a significant correlation $\left(R^{2}=0.938\right)$ with the experimental data. The obtained regression [(a) $\log K_{l}$ expt $=0.560 \times \log$ $\left.K_{l}{ }^{\text {calc }}\right]$ account for the deficiency of theoretical models in calculating $\log K_{I}$ values for complexation reactions with a change of the sum of absolute formal charges on reactants and products of $\Delta|q|=2$ and $\Delta|q|$ 
$=4$. For $\log K_{1}$ values spanning a range of nearly $17 \log$ units, the root-mean-square deviation (RMSD) is $1.34 \log$ units, which provides a computationally viable and relatively accurate method to predict the absolute values of stability constants for uranyl complexes.
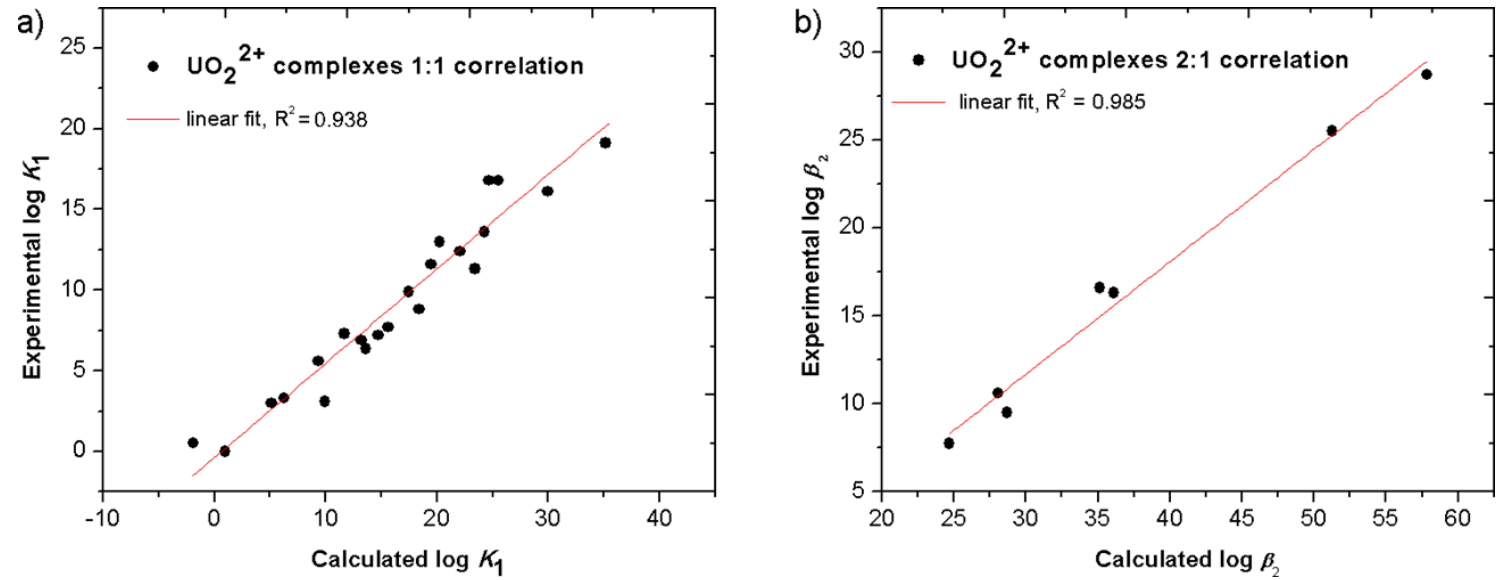

Figure 3. Plots of experimental $v s$. calculated stability constants values in aqueous solution for uranyl complexes with ligands depicted in Figure 2: (a) ligands 1a-22a (1:1 ligand:uranyl correlation) and (b) ligands 1b-7b (2:1 ligand:uranyl correlation). Equations for the regression lines: (a) $\log K_{l}^{\text {expt }}=0.560 \times \log K_{l}^{\text {calc }}$, with $\mathrm{R}^{2}=$ 0.938 ; (b) $\log K_{l}^{\text {expt }}=0.639 \times \log K_{l}^{\text {calc }}-7.484$, with $\mathrm{R}^{2}=0.985$.

Table 1. Comparison of experimental, calculated, and predicted $\log K_{l}$ values.

\begin{tabular}{|llllll|}
\hline ligand & expt. $^{a}$ & calc. $^{b}$ & abs. & pred. & abs. \\
& $\log K_{I}$ & $\log K_{I}$ & error & $\log K_{I}$ & error \\
1a acetate & 3.1 & 9.9 & 6.8 & 5.6 & 2.5 \\
2a acetylacetonate & 7.7 & 15.6 & 7.9 & 8.8 & 1.1 \\
3a phenolate & 6.4 & 13.6 & 7.2 & 7.6 & 1.3 \\
4a hydroxide & 8.8 & 18.4 & 9.6 & 10.3 & 1.5 \\
5a nitrate & 0 & 1.0 & 1.0 & 0.5 & 0.5 \\
6a chlorate & 0.5 & -1.9 & 2.4 & -1.1 & 1.6 \\
7a dihydrogen phosphate & 3.3 & 6.3 & 3.0 & 3.5 & 0.2 \\
8a acetamidoximate & 13.6 & 24.3 & 10.7 & 13.6 & 0.0 \\
9a benzamidoximate & 12.4 & 22.1 & 9.7 & 12.4 & 0.0 \\
10a salicylamidoximate & 16.1 & 30.1 & 14.0 & 16.9 & 0.8 \\
11a phthalimidedioximate & 16.8 & 25.5 & 8.7 & 14.3 & 2.5 \\
12a glutarimidedioximate $\left(\mathrm{HL}^{-}\right)$ & 11.3 & 23.4 & 12.1 & 13.1 & 1.8 \\
13a oxalate & 7.3 & 11.7 & 4.4 & 6.5 & 0.8 \\
14a phthalate & 5.6 & 9.4 & 3.8 & 5.3 & 0.3 \\
15a salicylate & 13 & 20.2 & 7.2 & 11.3 & 1.7 \\
16a catecholate & 16.8 & 24.7 & 7.9 & 13.8 & 3.0 \\
17a glutarimidedioximate $\left(\mathrm{L}^{2-}\right)$ & 19.1 & 35.2 & 16.1 & 19.7 & 0.6 \\
18a carbonate & 9.9 & 17.5 & 7.6 & 9.8 & 0.1 \\
19a sulfate & 3 & 5.2 & 2.2 & 2.9 & 0.1 \\
20a hydrogen phosphate & 7.2 & 14.7 & 7.5 & 8.3 & 1.1 \\
21a malonate & 6.9 & 13.2 & 6.3 & 7.4 & 0.5 \\
22a dipicolinate & 11.6 & 19.5 & 7.9 & 10.9 & 0.7 \\
\hline
\end{tabular}

${ }^{a}$ Corrected to zero ionic strength with the Davies equation. ${ }^{57}$

${ }^{b}$ Calculated using $\Delta G_{\text {aq. }}{ }^{c}$ Predicted from correlations shown in Figure 3a.

It is worth noting that the presented approach for predicting $\log K_{I}$ is equally applicable for assessing stability constants of 2:1 ligand:uranyl complexes, $\log \beta_{2}$. An example given in Table 2 illustrates that the model reproduces the experimentally reported $\log \beta_{2}$ values for the $\mathrm{UO}_{2}{ }^{2+}$ complexes with acetamidoxime and benzamidoxime ligands. However, this approach is not without limitations when it is used to evaluate 
stability constants of 2:1 complexes carrying an excess negative charge. As one may see from Table 2 exploiting the regression equation obtained from correlations of experimental and calculated $\log K_{l}$ (Figure $3 a)$ results in severe overestimation of $\log \beta_{2}$ values for the equilibrium shown in eq 12:

$$
\left[\mathrm{UO}_{2}\left(\mathrm{H}_{2} \mathrm{O}\right)_{5}\right]^{2+}+2 \mathrm{~L}^{2-} \rightleftharpoons\left[\mathrm{UO}_{2} \mathrm{~L}_{2}\left(\mathrm{H}_{2} \mathrm{O}\right)_{5-\mathrm{n}}\right]^{2-}+n \mathrm{H}_{2} \mathrm{O}
$$

Nevertheless, we found that the agreement with experimental data (Table 3) can be significantly improved by separate fitting of data for 2:1 uranyl complexes with negatively charged $\left(\mathrm{L}^{2-}\right)$ ligands depicted in Figure 2 b. Linear regression analysis (Figure $3 b$ ) suggests that $\log \beta_{2}$ of the $\left[\mathrm{UO}_{2} \mathrm{~L}_{2}\left(\mathrm{H}_{2} \mathrm{O}\right)_{5-\mathrm{n}}\right]^{2-}$ complexes should be better described by the regression equation [(b) $\left.\log K_{I}^{\text {expt }}=0.639 \times \log K_{I}^{\text {calc }}-7.484\right]$. Overall, the results verify that correlations obtained between DFT calculations and experiments can provide accurate predictions of $\log K_{l}$ values, allowing screening for new amidoxime-based ligands with strong uranyl ion binding. In addition, separate fitting of $\log \beta_{2}$ values for the uranyl complexes with excess negative charge extends the utility of our approach to predict the stability constants for 2:1 complexes, thereby providing opportunities for better understanding of uranyl complexation in seawater.

Table 2. Comparison of experimental and predicted $\log \beta_{2}$ values using 1:1 correlation from Figure $3 \mathrm{a}$.

\begin{tabular}{|llll|}
\hline ligand & expt. $^{a}$ & pred. $^{b}$ & abs. \\
& $\log \beta_{2}$ & $\log \beta_{2}$ & error \\
2acetamidoximate & 23.7 & 23.1 & 0.6 \\
2benzamidoximate & 22.3 & 21.1 & 1.2 \\
1b 2glutarimidedioximate & 28.7 & 32.4 & 3.7 \\
2b 2carbonate & 16.6 & 19.7 & 3.1 \\
3b 2salicylamidoximate & 25.5 & 28.7 & 3.2 \\
4b 2phthalate & 7.7 & 13.8 & 6.1 \\
5b 2dipicolinate & 16.3 & 20.2 & 3.9 \\
6b 2oxalate & 10.6 & 15.7 & 5.1 \\
7b 2malonate & 9.5 & 16.1 & 6.6 \\
\hline
\end{tabular}

${ }^{a}$ Corrected to zero ionic strength with the Davies equation. ${ }^{57}$

${ }^{b}$ Predicted from correlations shown in Figure 3a.

Table 3. Comparison of experimental and predicted $\log \beta_{2}$ values using 2:1 correlation from Figure $3 \mathrm{~b}$.

\begin{tabular}{|llll|}
\hline ligand & $\operatorname{expt.}^{a}$ & pred. $^{b}$ & abs. \\
& $\log \beta_{2}$ & $\log \beta_{2}$ & error \\
1b 2glutarimidedioximate & 28.7 & 29.5 & 0.8 \\
2b 2carbonate & 16.6 & 15.0 & 1.6 \\
3b 2salicylamidoximate & 25.5 & 25.3 & 0.2 \\
4b 2phthalate & 7.7 & 8.3 & 0.6 \\
5b 2dipicolinate & 16.3 & 15.6 & 0.7 \\
6b 2oxalate & 10.6 & 10.5 & 0.1 \\
7b 2malonate & 9.5 & 10.9 & 1.4 \\
\hline
\end{tabular}

${ }^{a}$ Corrected to zero ionic strength with the Davies equation. ${ }^{57}$

${ }^{b}$ Predicted from correlations shown in Figure $3 b$.

\subsubsection{Stability Constants of Vanadium Complexes}

Two sets, each consisting of 10 negative oxygen donor ligands depicted in Figure 4, were selected to test the ability of the adopted computational method to reproduce experimental stability constant values for the corresponding $\mathrm{VO}^{2+}$ and $\mathrm{VO}_{2}{ }^{+}$complexes. In contrast to the experimental data for uranium complexes available in the Smith and Martell's compilation of Critical Stability Constants series, ${ }^{51}$ the literature on the experimental $\log K_{1}$ values for $\mathrm{VO}^{2+}$ and $\mathrm{VO}_{2}{ }^{+}$complexes are quite limited, indicating that the accurate measurement of $\mathrm{VO}^{2+} / \mathrm{VO}_{2}{ }^{+}$stability constants is difficult. Results reported in other sources are often deficient in specifying essential reaction conditions (e.g., temperature, ionic strength, nature of supporting 
electrolyte) and cannot be recommended, for they cannot be reproduced in other laboratories. Unfortunately, much of the reported data for vanadium complexes falls into this category. Hence, the choice of this particular sets of ligands (Figure 4) was based on the availability of experimental aqueous stability constant data that meet the criteria for critical selection. ${ }^{51}$ In cases where $\log K_{l}$ values were not available at zero ionic strength, they were corrected to zero ionic strength using the Davies equation. ${ }^{57}$ The experimental $\log K_{1}$ values for $\mathrm{VO}^{2+}$ and $\mathrm{VO}_{2}{ }^{+}$complexes, spanning a range of nearly 11 orders of magnitude, are tabulated in Tables 4 and 5, respectively.

(a)<smiles>CC(=O)[O-]</smiles><smiles>CCC(=O)[O-]</smiles>

1a<smiles>O=C([O-])C(=O)[O-]</smiles><smiles>O=C([O-])CC(=O)[O-]</smiles>

6a<smiles>O=C([O-])CO</smiles>

3a<smiles>CCOC(=O)c1ccccc1C(=O)[O-]</smiles>

$8 \mathbf{a}$<smiles>O=C([O-])CS</smiles>

$4 a$<smiles>COC(=O)c1cccc(C(=O)OC)n1</smiles>

9a<smiles>O=[N+]([O-])[O-]</smiles>

4b

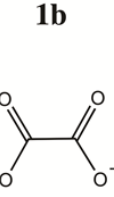

6b<smiles>CC(=O)[O-]</smiles>

2b<smiles>O=C([O-])CC(=O)[O-]</smiles>

$7 \mathrm{~b}$

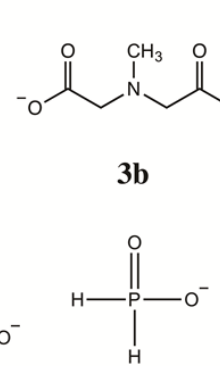

$8 \mathrm{~b}$<smiles>CCCCCP(=O)(=O)([O-])OC</smiles>

$5 a$<smiles></smiles>

10a<smiles>CC(C)S(=O)(=O)[O-]</smiles>

$5 \mathbf{b}$

Figure 4. Sets of negative oxygen donor ligands used to calculate stability constants, $\log K_{l}$, values for corresponding (a) oxovanadium (IV) and (b) dioxovanadium (V) complexes.

Table 4. Comparison of experimental, calculated, and predicted $\log K_{I}$ values for oxovanadium (IV) complexes with oxygen donor ligands.

\begin{tabular}{|llllll|}
\hline ligand & expt. $^{a}$ & calc. $^{b}$ & abs. & pred..$^{c}$ & abs. \\
& $\log K_{I}$ & $\log K_{I}$ & error & $\log K_{I}$ & error \\
1a acetate & 2.6 & 12.6 & 10.0 & 3.4 & 0.8 \\
2a chloroacetate & 1.7 & 7.4 & 5.7 & 2.0 & 0.3 \\
3a glycolate & 3.2 & 10.8 & 7.6 & 2.9 & 0.3 \\
4a thioglycolate & 8.8 & 33.3 & 24.5 & 9.1 & 0.3 \\
5a sulfate & 2.4 & 11.3 & 8.9 & 3.1 & 0.7 \\
6a oxalate & 7.0 & 22.1 & 15.1 & 6.0 & 1.0 \\
7a malonate & 6.7 & 23.7 & 17.0 & 6.5 & 0.2 \\
8a phthalate & 4.9 & 19.8 & 14.9 & 5.4 & 0.5 \\
9a dipicolinate & 8.0 & 28.8 & 20.8 & 7.8 & 0.2 \\
10a pyrazinecarboxylate & 3.9 & 13.3 & 9.4 & 3.6 & 0.3 \\
\hline
\end{tabular}

${ }^{a}$ Corrected to zero ionic strength with the Davies equation. ${ }^{57}$

${ }^{b}$ Calculated using $\Delta G_{a \mathrm{q}} .{ }^{c}$ Predicted from correlations shown in Figure 5.

Table 5. Comparison of experimental, calculated, and predicted $\log K_{l}$ values for dioxovanadium (V) complexes with oxygen donor ligands.

ligand expt. $^{a}{\text { calc }{ }^{b}}^{b}$ abs. pred. $^{c}$ abs.




\begin{tabular}{|llllll|}
\hline & $\log K_{I}$ & $\log K_{I}$ & error & $\log K_{I}$ & error \\
1b formate & 1.7 & 7.9 & 6.2 & 1.5 & 0.2 \\
2b acetate & 2.6 & 11.2 & 8.6 & 2.8 & 0.2 \\
3b methyliminodiacetate & 10.8 & 28.3 & 17.5 & 9.5 & 1.3 \\
4b nitrate & -0.2 & 0.5 & 0.7 & -1.4 & 1.2 \\
5b sulfate & 1.6 & 9.4 & 7.8 & 2.1 & 0.5 \\
6b oxalate & 6.6 & 18.3 & 11.7 & 5.6 & 1.0 \\
7b malonate & 5.2 & 19.4 & 14.2 & 6.0 & 0.8 \\
8b hypophosphite & 1.5 & 11.1 & 9.6 & 2.7 & 1.2 \\
9b hydrogen phosphate & 5.2 & 19.4 & 14.2 & 6.0 & 0.8 \\
10b dipicolinate & 9.3 & 28.6 & 19.3 & 9.6 & 0.3 \\
\hline
\end{tabular}

${ }^{a}$ Corrected to zero ionic strength with the Davies equation. ${ }^{57}$

${ }^{b}$ Calculated using $\Delta G_{\text {aq }}{ }^{c}$ Predicted from correlations shown in Figure 5.

Using an approach involving the application of a standard thermodynamic cycle (Figure 1), the complexation free energies in aqueous solution, $\Delta G_{\text {aq }}$, were evaluated according to equilibrium reactions given by eqs 13 and 14:

$$
\begin{aligned}
& {\left[\mathrm{VO}\left(\mathrm{H}_{2} \mathrm{O}\right)_{4}\right]^{2+}+\mathrm{L}^{x-} \rightleftharpoons\left[\operatorname{VOL}\left(\mathrm{H}_{2} \mathrm{O}\right)_{4-\mathrm{n}}\right]^{2-x}+n \mathrm{H}_{2} \mathrm{O}} \\
& {\left[\mathrm{VO}_{2}\left(\mathrm{H}_{2} \mathrm{O}\right)_{3}\right]^{+}+\mathrm{L}^{x-} \rightleftharpoons\left[\mathrm{VO}_{2} \mathrm{~L}\left(\mathrm{H}_{2} \mathrm{O}\right)_{3-\mathrm{n}}\right]^{1-x}+n \mathrm{H}_{2} \mathrm{O}}
\end{aligned}
$$

The $\Delta G_{\text {aq }}$ calculations require the global minimum geometries for each species. Given that the lowest energy configurations of solvated $\mathrm{VO}^{2+}$ and $\mathrm{VO}_{2}{ }^{+}$ions have been previously identified, ${ }^{60,61}$ and the free anionic ligands, $\mathrm{L}^{x-}$, are simple and rigid enough to be represented by a single conformation, the main issue was to find the most stable forms for $\left[\operatorname{VOL}\left(\mathrm{H}_{2} \mathrm{O}\right)_{4-\mathrm{n}}\right]^{2-x}$ and $\left[\mathrm{VO}_{2} \mathrm{~L}\left(\mathrm{H}_{2} \mathrm{O}\right)_{3-\mathrm{n}}\right]^{1-x}$ complexes. Since only the first coordination shell of the vanadium complexes was treated explicitly, it was possible to perform a systematic search of low-energy clusters for a given composition.

The bidentate coordination with the $\mathrm{VO}^{2+} / \mathrm{VO}_{2}{ }^{+}$ions was found to be predominant over the monodentate coordination that was observed only for the $\mathrm{VO}_{2}{ }^{+}$complex with a hypophosphite ligand. The complexation with ligands containing additional nitrogen donor atom, namely, methyliminodiacetate and dipicolinate (Figure 4), resulted in a tridentate binding to the vanadium ions. With respect to the number of water molecules bound to the vanadium atom, the results of calculations demonstrate that the most stable arrangement represents the five-coordinate structures. In other words, bidentate binding displaces two water molecules from the hydrated $\mathrm{VO}^{2+}$ and $\mathrm{VO}_{2}{ }^{+}$complexes leading to the formation of $\left[\mathrm{VOL}\left(\mathrm{H}_{2} \mathrm{O}\right)_{2}\right]^{2-x}$ and $\left[\mathrm{VO}_{2} \mathrm{~L}\left(\mathrm{H}_{2} \mathrm{O}\right)\right]^{1-x}$ species, respectively; whereas monodentate binding can replace only one water. The observed coordination number is in accord with crystal structure data showing that a coordination number five is typical for the vanadium complexes with rigid and sterically strained ligands. ${ }^{60,61}$

The calculated stability constant, $\log K_{I}$ calc, values for the $\mathrm{VO}^{2+}$ and $\mathrm{VO}_{2}{ }^{+}$complexes are summarized in Tables 4 and 5, respectively. As expected, our DFT-based method permitted reasonably good estimates of the relative binding strengths of $\mathrm{VO}^{2+}$ and $\mathrm{VO}_{2}{ }^{+}$complexes, while the absolute complexation energies were significantly overestimated, leading to inaccurately high $\log K_{l}$ values (calc. $\log K_{I}$ values in Tables 4 and 5). Consistent with DFT, high-level CCSD(T)/aug-cc-pvDZ//B3LYP/aug-cc-pvDZ calculations for acetate$\mathrm{VO}^{2+} / \mathrm{VO}_{2}{ }^{+}$and oxalate- $\mathrm{VO}^{2+} / \mathrm{VO}_{2}{ }^{+}$complexes also overestimated the log $K_{l}$ values, suggesting that the employed computational methodology (density functionals and basis sets) is not the main source of errors in the $\Delta G_{\text {aq }}$ calculations. The overestimated $\log K_{l}$ is the consequence of the simplification in solvent description used in our cluster models, since the solvation free energy of a multivalent ion is not fully accounted for by treating only the first hydration shell around the metal ion explicitly. ${ }^{62}$ However, accurate predictions of the absolute $\log K_{l}$ values (predicted $\log K_{l}$ in Tables 1 and 2) can still be obtained by fitting the experimental data for mono- and divalent negative oxygen donor ligands. 
Indeed, as follows from Figure 5, the theoretically calculated $\log K_{l}$ values show a very strong correlation with the experimental data (coefficients of determination: (a) $R^{2}=0.953$ and (b) $R^{2}=0.938$ ). Linear regression analysis suggests the following derived regression equations (15) and (16):

$$
\begin{aligned}
& \log K_{l}{ }^{\text {expt }}=0.272 \times \log K_{I}^{\text {calc }} \\
& \log K_{l}^{\text {expt }}=0.390 \times \log K_{I}^{\text {calc }}-1.583
\end{aligned}
$$

which essentially correct for deficiencies introduced by the solvation model and possess a significant predictive power. For the predicted $\log K_{l}$ values, the root-mean-square errors (RMSE) are only $0.53\left(\mathrm{VO}^{2+}\right)$ and $0.85\left(\mathrm{VO}_{2}^{+}\right) \log$ units, respectively, confirming that the presented computational method can provide accurate and reliable estimates of the absolute stability constant values for vanadium species.

a)

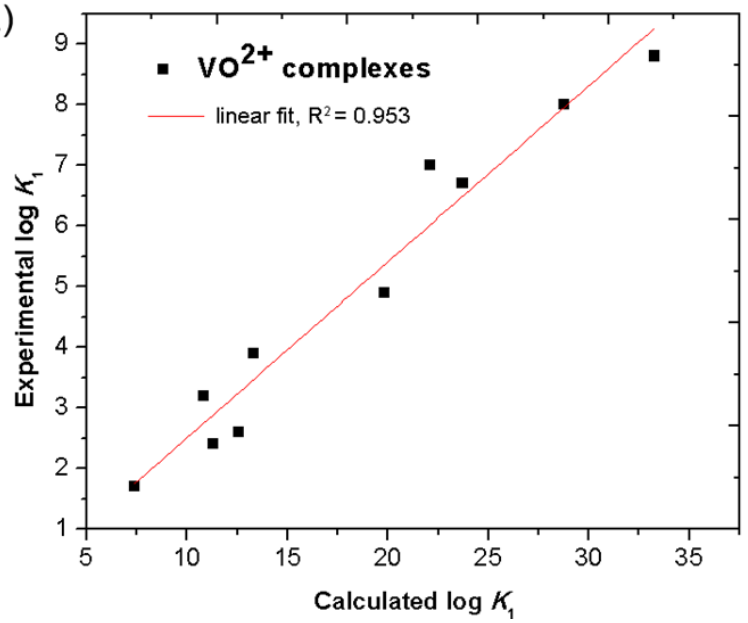

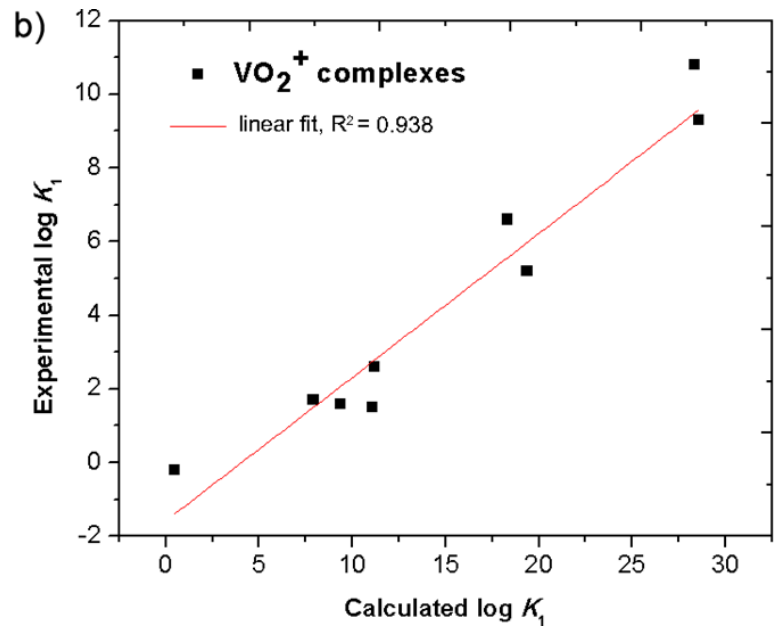

Figure 5. Plots of experimental vs. calculated $\log K_{l}$ values in aqueous solution for corresponding (a) oxovanadium (IV) and (b) dioxovanadium (V) complexes with oxygen donor ligands. Equations for the regression lines: (a) $\log K_{I}^{\text {expt }}=0.272 \times \log K_{I}^{\text {calc }}$, with $\mathrm{R}^{2}=0.953$; (b) $\log K_{I}^{\text {expt }}=0.390 \times \log K_{I}^{\text {calc }}-1.583$, with $\mathrm{R}^{2}=$ 0.938 .

\subsubsection{Assessing Ligand Selectivity for Uranium vs. Vanadium}

The difference between $\log K_{I}$ values for uranyl and oxovanadium ions can be used to assess the degree of ligand selectivity toward $\mathrm{UO}_{2}{ }^{2+} v s$. $\mathrm{VO}^{2+} / \mathrm{VO}_{2}{ }^{+}$. However, it is worth noting that the predicted $\log K_{1}$ values can deviate from experimental $\log K_{l}$ values, with absolute errors of more than $1.0 \log$ unit in some cases (Tables 1, 3, and 4). Since our main goal is to predict accurately the selectivity for $\mathrm{UO}_{2}{ }^{2+}$ over $\mathrm{VO}^{2+} / \mathrm{VO}_{2}{ }^{+}$ ions, it is important to check whether our predictions follow the experimental selectivity trend. Thus, we compared the predicted and experimental $\log K_{1}$ values for $\mathrm{UO}_{2}{ }^{2+}, \mathrm{VO}^{2+}$, and $\mathrm{VO}_{2}{ }^{+}$complexes with the same ligands. Histograms in Figure 6 verify that our theoretical results are generally in agreement with the experimental data, suggesting that the developed computational protocols for oxovanadium ions ${ }^{63}$ in conjunction with the analogous approach for predicting the stability constants for uranyl complexes ${ }^{56,64}$ can be a useful means of screening for new ligands with strong chelating capability to $\mathrm{UO}_{2}{ }^{2+} v s$. $\mathrm{VO}^{2+}$ and $\mathrm{VO}_{2}{ }^{+}$. 


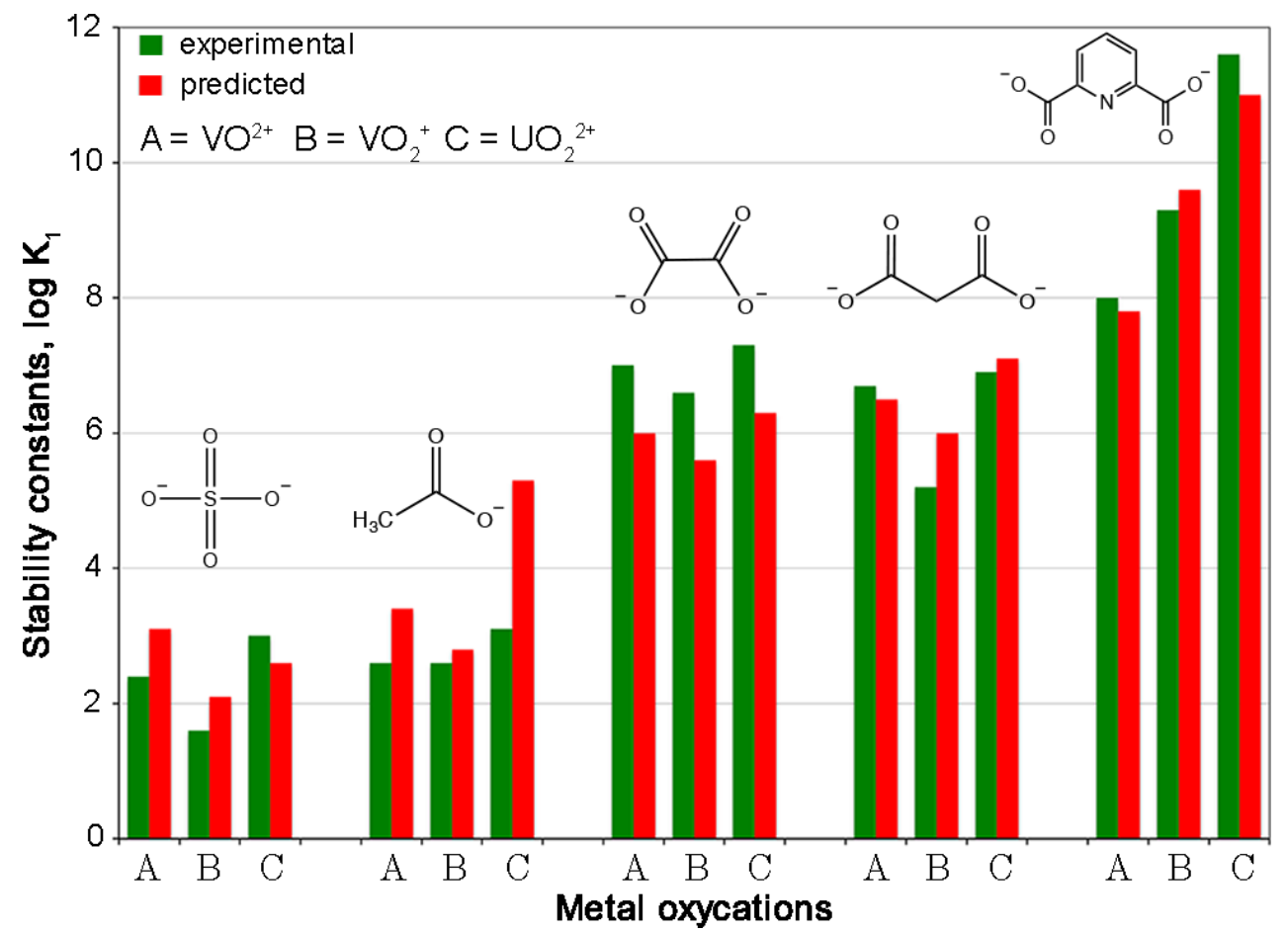

Figure 6. Histograms showing comparison of experimental (green) and predicted (red) $\log K_{l}$ values for A) $\mathrm{VO}^{2+}$, B) $\mathrm{VO}_{2}{ }^{+}$, and C) $\mathrm{UO}_{2}{ }^{2+}$ complexes with identical ligands.

Having developed a $\log K_{l}$ calculation method that achieves good accuracy, we can now begin to examine the trends in selectivity for potential ligands that would possess higher binding affinity to $\mathrm{UO}_{2}{ }^{2+} v s$. $\mathrm{VO}^{2+}$ and $\mathrm{VO}_{2}{ }^{+}$ions. Amidoxime-based ligands are of special interest because of their ability to extract uranium under seawater conditions ${ }^{11-13}$ and they will be considered in more detail in the next chapter of this report. It is also known that the incorporation of acidic groups such as acrylate and itaconate into a poly(acrylamidoxime) adsorbent is crucial to obtain a high uranium uptake.

Although hydrophilic carboxylate ligands have been suggested to help seawater to access the amidoxime groups on the graft chain, ${ }^{65,66}$ the exact mechanism has not yet been fully established and understood. According to some experimenta ${ }^{67}$ and theoretical ${ }^{68}$ studies, carboxylic acid functional groups can also directly participate in binding with uranyl ions. In an effort to probe the complexing properties of simple dicarboxylate ligands, we have assessed the stability constant, $\log K_{l}$, values for the $\mathrm{UO}_{2}{ }^{2+}, \mathrm{VO}_{2}{ }^{+}$, and $\mathrm{VO}^{2+}$ complexes with oxalic, malonic, succinic, and glutaric acids.

In contrast to the experimental data for the uranium complexes available in the Smith and Martell compilation series, ${ }^{51}$ the $\log K_{l}$ values for the $\mathrm{VO}_{2}{ }^{+}$and $\mathrm{VO}^{2+}$ complexes are available only for oxalic and malonic ligands. To supplement this lack of data, we have applied our approach to estimate and compare the equilibrium constants for the formation of $\mathrm{VO}_{2}{ }^{+}$and $\mathrm{VO}^{2+}$ complexes with the aforementioned dicarboxylic ligands. The $\log K_{1}$ values of the $\mathrm{UO}_{2}{ }^{2+}$ complexes were also theoretically calculated to make sure that the adopted computational method is capable of reproducing experimental $\log K_{l}$ data for the complexes with dicarboxylic ligands having a long alkyl chain. The most stable geometries of the complexes were used to compute the corresponding free energies in aqueous solution, $\Delta G_{\text {aq }}$, and stability constants, $\log K_{l}$. According to our calculations, the dicarboxylic acids form stronger complexes with $\mathrm{UO}_{2}{ }^{2+}, \mathrm{VO}_{2}{ }^{+}$, and $\mathrm{VO}^{2+}$ ions through chelation involving both carboxylate functional groups. The results of the $\log K_{l}$ calculations for the dicarboxylic ligands are summarized in Table 6. 
Table 6. Experimental and theoretically calculated $\log K_{l}$ values for uranyl, dioxovanadium (V), and oxovanadium (IV) complexes with dicarboxylate ligands.

\begin{tabular}{|l|ll|ll|ll|}
\hline \multirow{2}{*}{ ligand } & \multicolumn{6}{c|}{$\log K_{1}$} \\
\cline { 2 - 7 } & \multicolumn{2}{|c|}{$\mathrm{UO}_{2}^{2+}$} & \multicolumn{2}{|c|}{ VO $_{2}{ }^{+}$} & \multicolumn{2}{c|}{ VO $^{2+}$} \\
I oxalate & 7.3 & 6.6 & 6.6 & 5.6 & 7.0 & 6.0 \\
II malonate & 6.9 & 7.0 & 5.2 & 5.6 & 6.7 & 6.2 \\
III succinate & 5.2 & 4.9 & - & 6.8 & - & 5.4 \\
IV glutarate & 4.8 & 4.5 & - & 6.6 & - & 4.9 \\
V itaconate & 5.8 & 5.1 & - & 6.7 & - & 5.3 \\
VI 2,2- & - & 6.4 & - & 7.7 & - & 6.1 \\
dimethyl- & & & & & & \\
succinate & & & & & & \\
\hline
\end{tabular}

${ }^{a}$ Corrected to zero ionic strength with the Davies equation. ${ }^{57}$ The corresponding experimental data for the $\mathrm{VO}_{2}{ }^{+}$and $\mathrm{VO}^{2+}$ complexes with ligands III-VI are not available.

${ }^{\mathrm{b}}$ Calculated using the developed methodology.

As one may see, our theoretical protocol provides a good estimate of the $\log K_{l}$ values for the considered set of ligands, with the maximum absolute error up to $1 \log$ unit. In order to find the trend in the relative binding affinity and selectivity of the dicarboxylate ligands we have compared $\log K_{l}$ values for the corresponding $\mathrm{UO}_{2}{ }^{2+}, \mathrm{VO}_{2}{ }^{+}$, and $\mathrm{VO}^{2+}$ complexes. A histogram of the calculated $\log K_{l}$ values for the metal oxycation complexes as a function of the length of the ligand's aliphatic chain (Figure 7, ligands: I-IV) shows that more flexible ligands tend to form weaker complexes with $\mathrm{UO}_{2}{ }^{2+}$ and $\mathrm{VO}^{2+}$ cations. However, the opposite trend is observed for the complexes with $\mathrm{VO}_{2}{ }^{+}$, suggesting that increasing the number of alkyl groups in the aliphatic chain can lead to a positive effect on the stability of the $\mathrm{VO}_{2}{ }^{+} /$dicarboxylate systems.

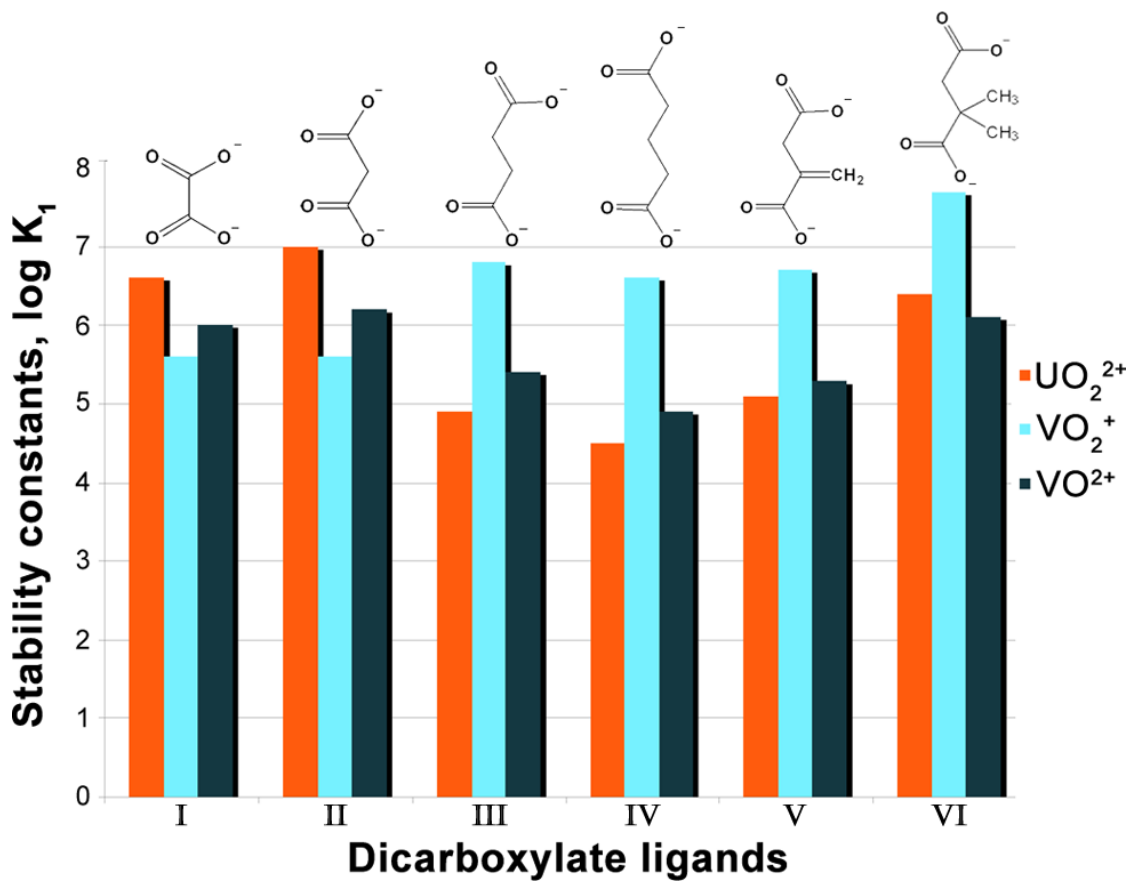

Figure 7. Comparison of theoretically predicted $\log K_{1}$ values for $\mathrm{UO}_{2}{ }^{2+}$ (red), $\mathrm{VO}_{2}{ }^{+}$(turquoise), and $\mathrm{VO}^{2+}$ (dark blue) complexes with dicarboxylate ligands: I) oxalate, II) malonate, III) succinate, IV) glutarate, V) itaconate (2-methylenesuccinate), VI) 2,2-dimethylsuccinate.

The $\log K_{1}$ values for the $\mathrm{UO}_{2}{ }^{2+}, \mathrm{VO}_{2}{ }^{+}$, and $\mathrm{VO}^{2+}$ complexes with itaconic acid (Figure 7, structure $\mathrm{V}$ ) were also theoretically assessed (see Table 6). Itaconic acid, which contains a vinyl group connected directly to a succinic acid terminus, is often used as a co-monomer in the synthesis of poly(acrylamidoxime) 
adsorbents for the extraction of uranium from seawater. Since in the actual adsorbent the vinyl group is polymerized to give a branched polyethylene, aliphatic 2,2-dimethylsuccinic acid (Figure 7, structure VI) would be a more accurate model representation of itaconic acid grafted on a fiber. Theoretically predicted $\log K_{1}^{\text {pred }}$ value of the $\mathrm{VO}_{2}{ }^{+}$complex with VI is 1.3 and $1.6 \mathrm{log}$ units higher than that of the $\mathrm{UO}_{2}{ }^{2+}$ and $\mathrm{VO}^{2+}$ complexes, respectively, indicating higher selectivity of VI towards $\mathrm{VO}_{2}{ }^{+}$over $\mathrm{UO}_{2}{ }^{2+}$ and $\mathrm{VO}^{2+}$ ions.

Interestingly, recent experimental studies on the performance of poly(acrylamidoxime) adsorbent show higher vanadium uptake selectivity over uranium, irrespective of the molar ratio of amidoxime and itaconic acid used for adsorbent grafting the adsorbent with different mole ratios of amidoxime and itaconic acid. ${ }^{66}$ Overall, our results suggest that simple aliphatic dicarboxylic ligands possess low binding affinity and selectivity for uranyl, because their backbones present architectures that are poorly organized for the $\mathrm{UO}_{2}{ }^{2+}$ complexation. Indeed, the two carboxyl groups of the lowest-energy conformers of the dycarboxylic acids point in opposite directions such that it is not possible for the two oxygen atoms to simultaneously contact the metal ion. Therefore, the dicarboxylate structure must adopt a higher-energy conformation to allow chelation. Our calculations show that in addition to the entropically disfavored restricted rotation about C$\mathrm{C}$ bonds, the structural changes induced by metal chelation lead to increasing ligand strain, with a strain energy, $\Delta E_{\text {reorg }}\left(E_{\text {bound }}-E_{\text {free }}\right)$, of $39.50 \mathrm{kcal} / \mathrm{mol}$ for the least preorganized glutarate ligand, which exhibits the smallest stability constant value with $\mathrm{UO}_{2}{ }^{2+}\left(\log K_{I}\right.$ pred $\left.=4.5\right)$.

The foregoing analysis suggests that a considerable enhancement in binding affinity and selectivity for uranyl over vanadium ions can be achieved if the dycarboxylates are conformatially constrained in a favorable host architecture that is structurally organized for binding with $\mathrm{UO}_{2}{ }^{2+}$, thereby eliminating unfavorable entropic and enthalpic (strain energy) terms. We decided to test the highly preorganized ligand PDA (1,10-phenanthroline-2,9-dicarboxylic acid) (Figure 8), because it possesses a high complexing power for large metal ions. ${ }^{69-71}$

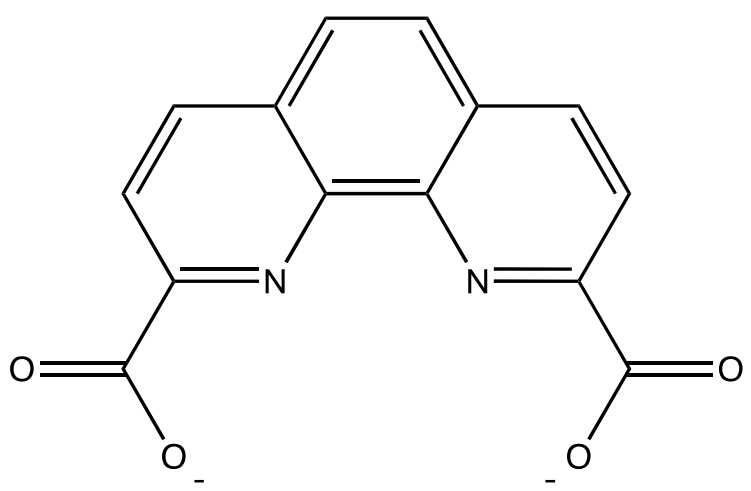

Figure 8. PDA (1,10-phenanthroline-2,9-dicarboxylic acid).

The advantage of our computational approach is that we can quickly assess the selectivity of a ligand toward $\mathrm{U} v s$. V without any prior experimental data. Thus we employed our methodology to predict $\log K_{l}$ for the corresponding complexes. DFT calculations were performed to elucidate the optimal coordination modes and geometries of uranyl, vanadate(V), and vanadyl(IV) complexes with PDA. The most stable structures of the complexes are shown in Figure 9.

Consistent with previous single-crystal X-ray diffraction data, ${ }^{70}$ our calculations show that the PDA anion is bound to the uranyl cation in a tetradentate fashion through both nitrogen atoms at an average distance of $2.56 \AA$ and through two carboxylate oxygen atoms at an average distance of $2.34 \AA$ (Figure 9a). It is noteworthy that the PDA ligand in the $\mathrm{UO}_{2}{ }^{2+} / \mathrm{PDA}$ complex is almost exactly planar, with the uranium atom lying in the plane of the ligand, which suggests that the PDA is highly preorganized for uranyl complexation and tends to coordinate to $\mathrm{UO}_{2}{ }^{2+}$ in a low-strain manner. While X-ray diffraction studies ${ }^{70}$ of $\mathrm{UO}_{2}{ }^{2+} / \mathrm{PDA}$ 
indicate that the uranyl ion is five-coordinate, the preferred coordination number for the corresponding species in water has not yet been identified. Thus, we used DFT calculations (M06 and SMD) to determine the most stable coordination environment in aqueous solution. The free energy change, $\Delta G_{\text {aq }}$, calculated for the equilibrium shown by eq (17):

$$
\left.\left[\mathrm{UO}_{2}(\mathrm{PDA})\left(\mathrm{H}_{2} \mathrm{O}\right)\right]+\mathrm{H}_{2} \mathrm{O} \text { 的 } \mathrm{UO}_{2}(\mathrm{PDA})\left(\mathrm{H}_{2} \mathrm{O}\right)_{2}\right], \Delta G_{\mathrm{aq}}=+4.52 \mathrm{kcal} / \mathrm{mol}
$$

suggests that the five-coordinate structure (Figure 9a) is more thermodynamically stable than the sixcoordinate $\mathrm{UO}_{2}^{2+} / \mathrm{PDA}$ with two water molecules bound to $\mathrm{UO}_{2}{ }^{2+}$.

The structure of the $\mathrm{VO}_{2}{ }^{+}$complex of PDA (Figure $9 \mathrm{~b}$ ) confirms our expectations that vanadium (V) would be too small to accommodate simultaneous binding of all four donor atoms of PDA. Our initial structure for a DFT optimization, consisting of the $\mathrm{VO}_{2}{ }^{+}$bonded to all four donor atoms of PDA and one water molecule, refined to a structure with only three-coordinating PDA (Figure 9b), with one carboxylate group left non-coordinated and hydrogen-bonded to a water on the $\mathrm{VO}_{2}{ }^{+}$. Although our calculations for the $\mathrm{VO}_{2}{ }^{+} / \mathrm{PDA}$ complex without any additional water molecules converge to a local minimum with fourcoordinating PDA, the formation of [ $\left.\mathrm{VO}_{2}(\mathrm{PDA})\right]^{-}$is less thermodynamically favorable compared to the $\left[\mathrm{VO}_{2}(\mathrm{PDA})\left(\mathrm{H}_{2} \mathrm{O}\right)\right]^{-}$complex, as follows from the negative $\Delta G_{\text {aq }}$ value for eq (18):

$$
\left.\left[\mathrm{VO}_{2}(\mathrm{PDA})\right]^{-}+\mathrm{H}_{2} \mathrm{O} \text { 和 }{ }_{2}(\mathrm{PDA})\left(\mathrm{H}_{2} \mathrm{O}\right)\right]^{-}, \Delta G_{\mathrm{aq}}=-5.33 \mathrm{kcal} / \mathrm{mol}
$$

In contrast to vanadium(V), vanadium(IV) is able to coordinate with all four donor atoms of PDA simultaneously. The five-coordinate vanadium(IV) complex, [VO(PDA)], in Figure 9c was found to be $\sim 10 \mathrm{kcal} / \mathrm{mol}$ more stable than the corresponding six-coordinate [VO $\left.(\mathrm{PDA})\left(\mathrm{H}_{2} \mathrm{O}\right)\right]$ complex with an additional water bonded to the vanadium metal center:

$$
[\mathrm{VO}(\mathrm{PDA})]+\mathrm{H}_{2} \mathrm{O}\left[\mathrm{VO}(\mathrm{PDA})\left(\mathrm{H}_{2} \mathrm{O}\right)\right], \Delta G_{\mathrm{aq}}=+10.42 \mathrm{kcal} / \mathrm{mol}
$$

However, thorough examination of the [VO(PDA)] structure indicates that the ionic radius of vanadium(IV) is still small for an ideal coordination in the cleft of PDA, because the $\mathrm{VO}^{2+}$ cation induces deviation from planarity and distortions in the PDA ligand upon binding (Figure 9c). Our calculations at the M06/SSC/6$311++\mathrm{G}(\mathrm{d}, \mathrm{p})$ level of theory show that the PDA ligand strain energy upon binding with $\mathrm{VO}^{2+}$ is as much as $34.78 \mathrm{kcal} / \mathrm{mol}$ higher than the strain energy associated with negligible structural changes of PDA when binding the $\mathrm{UO}_{2}{ }^{2+}$ cation.

(a)

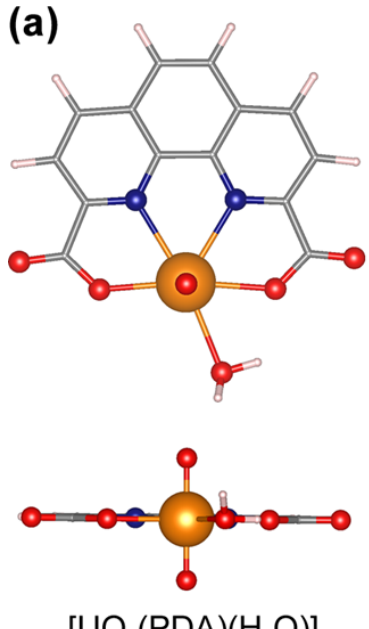

$\left[\mathrm{UO}_{2}(\mathrm{PDA})\left(\mathrm{H}_{2} \mathrm{O}\right)\right]$ (b)
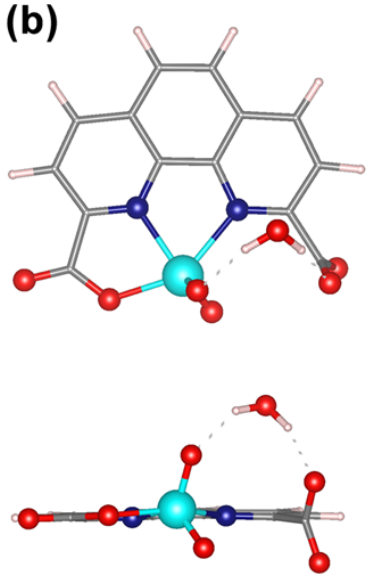

$\left[\mathrm{VO}_{2}(\mathrm{PDA})\left(\mathrm{H}_{2} \mathrm{O}\right)\right]^{-}$ (c)
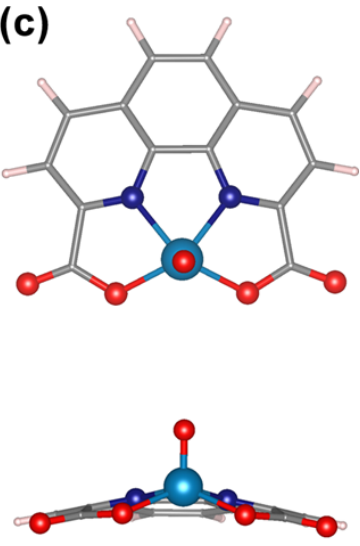

[VO(PDA)] 
Figure 9. Top and side views of the fully optimized geometries (M06/SSC/6-311++G(d,p)) of aqueous 1:1 (a) $\mathrm{UO}_{2}{ }^{2+} / \mathrm{PDA}$, (b) $\mathrm{VO}_{2}{ }^{+} / \mathrm{PDA}$, and (c) $\mathrm{VO}^{2+} / \mathrm{PDA}$ complexes. Color legend: $\mathrm{O}$, red; $\mathrm{N}$, navy blue; $\mathrm{C}$, grey; $\mathrm{H}$, white; $\mathrm{V}(\mathrm{V})$, turquoise; $\mathrm{V}(\mathrm{IV})$, blue; $\mathrm{U}$, orange.

The most stable forms of the $\mathrm{UO}_{2}{ }^{2+}, \mathrm{VO}_{2}{ }^{+}$, and $\mathrm{VO}^{2+}$ complexes with PDA were used for calculations of their individual stability constant $\left(\log K_{l}\right)$. As one may see from Table 7 , the $\log K_{l}$ value of $\left[\mathrm{UO}_{2}(\mathrm{PDA})\left(\mathrm{H}_{2} \mathrm{O}\right)\right]$ is significantly greater in magnitude than the $\log K_{l}$ values of the vanadium complexes with PDA. Therefore, our results indicate that the PDA ligand is better organized for binding with large $\mathrm{UO}_{2}{ }^{2+}$ than with small $\mathrm{VO}_{2}{ }^{+}$and $\mathrm{VO}^{2+}$ cations. In spite of the fact that $\mathrm{VO}^{2+}$ is able to coordinate to all four donor atoms of PDA, this induces high ligand strain resulting in a low $\log K_{l}$ value, which is similar to that of the $\mathrm{VO}_{2}{ }^{+} / \mathrm{PDA}$ complex.

Finally, in order to confirm the predicted $\log K_{I}$ values, thorough experimental investigations of $\mathrm{UO}_{2}{ }^{2+}$, $\mathrm{VO}_{2}{ }^{+}$, and $\mathrm{VO}^{2+}$ complexes with PDA have been performed using a combination of fluorescence and absorbance techniques. ${ }^{72}$ The results given in Table 7 verify that our computational protocol provides very accurate estimates of the $\log K_{l}$ values (with the maximum absolute error of $0.5 \log$ units) for 1:1 $\left[\mathrm{UO}_{2}(\mathrm{PDA})\left(\mathrm{H}_{2} \mathrm{O}\right)\right],\left[\mathrm{VO}_{2}(\mathrm{PDA})\left(\mathrm{H}_{2} \mathrm{O}\right)\right]^{-}$, and [VO(PDA)] complexes. Mutual consistency of experimental and theoretically predicted stability constant values of the PDA complexes further confirms the validity of the developed approach for predicting $\log K_{l}$.

Table 7. Experimental and theoretically calculated $\log K_{I}$ values for uranyl, dioxovanadium(V), and oxovanadium(IV) complexes with the PDA ligand.

\begin{tabular}{|llll|}
\hline & \multicolumn{3}{c|}{$\log K_{l}$} \\
complex & expt. & pred. & abs. \\
& & & error \\
{$\left[\mathrm{UO}_{2}(\mathrm{PDA})\left(\mathrm{H}_{2} \mathrm{O}\right)\right]$} & 16.5 & 16.0 & 0.5 \\
{$\left[\mathrm{VO}_{2}(\mathrm{PDA})\left(\mathrm{H}_{2} \mathrm{O}\right)\right]^{-}$} & 7.3 & 7.2 & 0.1 \\
{$[\mathrm{VO}(\mathrm{PDA})]$} & 7.4 & 7.5 & 0.1 \\
\hline
\end{tabular}

In seawater, one has to take into account the carbonate complexes and the relatively high concentration of carbonate of $\sim 2.5 \times 10^{-3} \mathrm{M}$. In order to test whether the PDA functionality could compete with $\mathrm{CO}_{3}{ }^{2-}$ ions for complexation with $\mathrm{UO}_{2}{ }^{2+}$, a species distribution diagram was constructed by incorporating the $\log K_{I}$ values for the carbonate complexes of $\mathrm{UO}_{2}{ }^{2+}, \mathrm{VO}_{2}{ }^{+}$, and $\mathrm{VO}^{2+}$, together with all the hydrolysis constants known for these metal ions ${ }^{51,73-75}$ as well as the $\log K_{l}$ values for the PDA complexes. Even in the presence of $0.001 \mathrm{M}$ PDA (low concentration), $\mathrm{UO}_{2}{ }^{2+}$ is fully (100\%) complexed by the ligand. The inclusion of carbonate complexes made little difference to the species distribution diagram for $\mathrm{VO}_{2}{ }^{+}$, so that even without the inclusion of competing $\mathrm{UO}_{2}{ }^{2+}$, the $\mathrm{VO}_{2}{ }^{+}$cation forms no complexes with PDA at $\mathrm{pH}$ 8. These are completely suppressed at this $\mathrm{pH}$ by the formation of the very stable $\mathrm{H}_{2} \mathrm{VO}_{4}{ }^{-}$anion.

Experimentation with the $\mathrm{VO}^{2+} / \mathrm{PDA}$ system shows that with the inclusion of carbonate at a relatively high concentration of $2.5 \times 10^{-3} \mathrm{M}$ as found in seawater, the [VO(PDA)] complex is largely suppressed. One can thus conclude with confidence that that the PDA ligand would exclusively bind $\mathrm{UO}_{2}{ }^{2+}$ under seawater conditions. It is worth mentioning that the low hydrophilicity of the PDA aromatic backbone may be the major challenge associated with the successful operation of the potential PDA-based polymer adsorbents. However, functionalizing the phen backbone with amines or alcohols can be sufficient to improve the solubility of PDA while increasing its electron donation properties and thus $\mathrm{UO}_{2}{ }^{2+}-\mathrm{PDA}$ bond strength. Hence, we expect that ion-exchange materials based on a PDA functional group would be highly efficient and selective for $\mathrm{UO}_{2}{ }^{2+}$ over the vanadium species present in seawater.

An important result from our studies of PDA is that it has several advantages over a glutarimidedioxime ligand, which is reputedly responsible for the extraction of uranium from seawater using the current state 
of the art amidoxime-based adsorbents. ${ }^{53}$ For instance, glutarimidedioxime is highly unstable under strongly alkaline or acidic stripping conditions and has the drawback of low selectivity for uranium over vanadium cations. ${ }^{76}$ In contrast, PDA shows no sign of decomposition on standing in $\mathrm{HNO}_{3}$ or $\mathrm{NaOH}$ for three months. Moreover, PDA exhibits strong size-based selectivity in that the determined $\log K_{l}$ values of the PDA complexes of the vanadium ions are low $\left(\log K_{I}=7.3\left(\mathrm{VO}_{2}^{+}\right)\right.$and $\left.7.4\left(\mathrm{VO}^{2+}\right)\right)$ and the ligand is expected to be stable during $\mathrm{UO}_{2}{ }^{2+}$ stripping from the adsorbent, which should occur in basic solution of $\mathrm{pH} \sim 12$. Overall, due to its high chemical stability and selectivity for uranyl, PDA is a very promising candidate for the development of novel adsorbent materials for the selective extraction of uranium from seawater. Efforts on the incorporation of PDA into a polymer fiber are underway in our laboratory.

\subsubsection{Role of Open-Chain and Cyclic Amidoxime Functionalities in Selectivity}

While the synthesis and subsequent grafting of new ligands on a polymer fiber can be a time consuming process, optimizing the current poly(acrylamidoxime) sorbent characteristics to favor uranium vs. vanadium sorption is a more straightforward task. A typical poly(acrylamidoxime) sorbent material contains polyethylene or polypropylene as a trunk polymer and amidoximated polyacrylonitrile copolymerized with hydrophilic groups (e.g., acrylic, methacrylic, itaconic acids) as a graft chain (Figure 10). According to the previous experimental studies, ${ }^{77,78}$ conversion of polyacrylonitrile to polyamidoxime leads to the simultaneous formation of open-chain amidoxime and cyclic imide dioxime functionalities and the relative yields of these two functional groups strongly depends on the synthesis conditions. ${ }^{78}$ Thus, quantification and comparison of the binding strengths of the open-chain amidoxime and the cyclic imide dioxime towards uranium $v s$. vanadium could help to optimize the grafting process and improve the efficiency of the selective extraction of uranium.

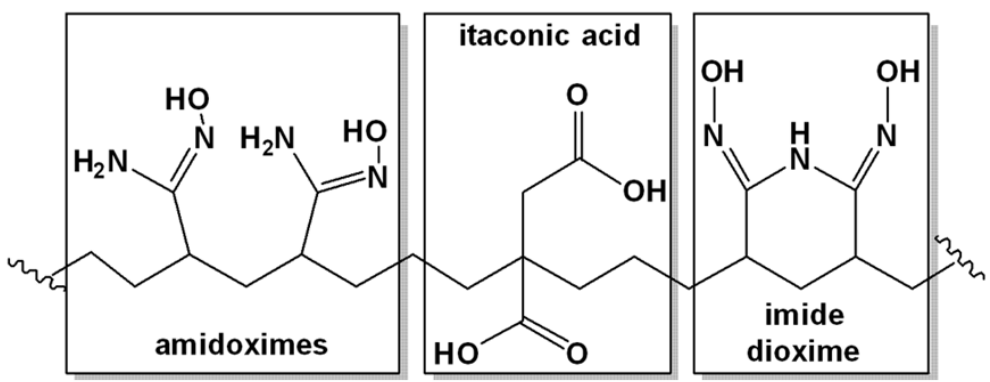

Figure 10. Schematic depiction of a small subsection of the poly(acrylamidoxime) fiber.

To quantify and compare the binding strengths and selectivity of different functional groups, the stability constants of two small molecular ligands, acetamidoximate ( $\mathrm{AO}^{-}$) and glutarimidedioximate (IDO ${ }^{2-}$ ) (Figure 11) were computationally assessed using the developed protocols.

a)<smiles>C/C(N)=N/[O-]</smiles>

AO-<smiles>[O-]/N=C1/CCCC(N[O-])=N1</smiles>

IDO $^{2-}$

Figure 11. (a) Acyclic acetamidoximate ( $\mathrm{AO}^{-}$) and (b) cyclic glutarimidedioximate (IDO') ${ }^{2-}$ ligands.

Table 8 summarizes the stability constants of the corresponding uranyl complexes with the $\mathrm{AO}^{-}$and $\mathrm{IDO}^{2-}$ ligands. Although the experimental results on $\mathrm{AO}^{-}$and $\mathrm{IDO}^{2-}$ complexation with uranyl have been reported,,$^{53,54}$ our computational approach enabled us to estimate stability constants for the formation of 
$\left[\mathrm{UO}_{2}(\mathrm{AO})_{3}\right]^{-}, \quad\left[\mathrm{UO}_{2}(\mathrm{AO})\left(\mathrm{CO}_{3}\right)\right]^{-}, \quad\left[\mathrm{UO}_{2}(\mathrm{AO})_{2}\left(\mathrm{CO}_{3}\right)\right]^{2-}, \quad\left[\mathrm{UO}_{2}(\mathrm{IDO})\left(\mathrm{CO}_{3}\right)\right]^{2-}$, and $\left[\mathrm{UO}_{2}(\mathrm{HIDO})\left(\mathrm{CO}_{3}\right)\right]^{-}$ species, thus providing a more detailed picture of uranium complexation in the presence of high concentration of carbonate ions $\left(\mathrm{C}_{\text {carbonate }}\right)$, which is relevant to seawater conditions. ${ }^{79}$

Table 8. Equilibrium constants for the $\mathrm{UO}_{2}^{2+} / \mathrm{AO}^{-}$and $\mathrm{UO}_{2}^{2+} / \mathrm{IDO}^{2-}$ complexes, all at $25^{\circ} \mathrm{C}$ and zero ionic strength.

\begin{tabular}{|c|c|}
\hline aqueous species, reactions & $\log \beta$ \\
\hline acetam & \\
\hline $\mathrm{UO}_{2}^{2+}$ & $13.6^{\mathrm{a}}$ \\
\hline $\mathrm{UO}_{2}^{2+}+2 \mathrm{AO}^{-}\left[\mathrm{UO}_{2}(\mathrm{AO})_{2}\right]$ & $23.7^{\mathrm{a}}$ \\
\hline $\mathrm{UO}_{2}^{2+}+3 \mathrm{AO}^{-1}\left[\mathrm{UO}_{2}(\mathrm{AO})_{3}\right]^{-}$ & $27.9^{\mathrm{b}}$ \\
\hline $\mathrm{UO}_{2}^{2+}+\mathrm{AO}^{-}+\mathrm{CO}_{3}^{2-}\left[\mathrm{UO}_{2}(\mathrm{AO})\left(\mathrm{CO}_{3}\right)\right]^{-}$ & $15.8^{\mathrm{b}}$ \\
\hline $\begin{array}{l}\mathrm{UO}_{2}{ }^{2+}+2 \mathrm{AO}^{-}+\mathrm{CO}_{3}^{2-}\left[\mathrm{UO}_{2}(\mathrm{AO})_{2}\left(\mathrm{CO}_{3}\right)\right]^{2-} \\
\text { glutarimidedioximate }\left(\mathrm{IDO}^{2-}\right) \text { ligand. }\end{array}$ & $25.5^{\mathrm{b}}$ \\
\hline $\mathrm{UO}_{2}^{2+}+\mathrm{IDO}^{2-}\left[\mathrm{UO}_{2}(\mathrm{IDO})\right]$ & $19.2^{\mathrm{a}}$ \\
\hline $\mathrm{UO}_{2}^{2+}+\mathrm{H}^{+}+\mathrm{IDO}^{2-}\left[\mathrm{UO}_{2}(\mathrm{HIDO})\right]^{+}$ & $23.5^{\mathrm{a}}$ \\
\hline $\mathrm{UO}_{2}^{2+}+2 \mathrm{IDO}^{2-}\left[\mathrm{UO}_{2}(\mathrm{IDO})_{2}\right]^{2-}$ & $29.0^{\mathrm{a}}$ \\
\hline $\mathrm{UO}_{2}^{2+}+\mathrm{H}^{+}+2 \mathrm{IDO}^{2-}\left[\mathrm{UO}_{2}(\mathrm{HIDO})(\mathrm{IDO})\right]^{-}$ & $38.9^{\mathrm{a}}$ \\
\hline $\mathrm{UO}_{2}^{2+}+2 \mathrm{H}^{+}+2 \mathrm{IDO}^{2-}\left[\mathrm{UO}_{2}(\mathrm{HIDO})_{2}\right]$ & $44.2^{\mathrm{a}}$ \\
\hline $\mathrm{UO}_{2}{ }^{2+}+\mathrm{IDO}^{2-}+\mathrm{CO}_{3}^{2-}\left[\mathrm{UO}_{2}(\mathrm{IDO})\left(\mathrm{CO}_{3}\right)\right]^{2-}$ & $25.2^{\mathrm{b}}$ \\
\hline $\mathrm{UO}_{2}^{2+}+\mathrm{H}^{+}+\mathrm{IDO}^{2-}+\mathrm{CO}_{3}^{2-}\left[\mathrm{UO}_{2}(\mathrm{HIDO})(\mathrm{C}\right.$ & $29.2^{\mathrm{b}}$ \\
\hline
\end{tabular}

${ }^{a}$ Taken from ref. 46,47 and corrected to zero ionic strength with the Davies equation. ${ }^{57}$

${ }^{b}$ Predicted from correlations shown in Figure 3.

The predominant species of uranium under seawater conditions are ternary complexes, $\left[\mathrm{Ca}_{2}\left(\mathrm{UO}_{2}\right)\left(\mathrm{CO}_{3}\right)_{3}\right]$ and $\left[\mathrm{Mg}\left(\mathrm{UO}_{2}\right)\left(\mathrm{CO}_{3}\right)_{3}\right]^{2-}$, as well as tricarbonato complex, $\left[\mathrm{UO}_{2}\left(\mathrm{CO}_{3}\right)_{3}\right]^{4-} .80$ As a result, an effective sequestering agent must be able to compete with magnesium, calcium, and carbonate ions for complexing $\mathrm{UO}_{2}{ }^{2+}$ at seawater $\mathrm{pH}$. Using the stability constants of $\mathrm{UO}_{2}{ }^{2+}$ complexes with acetamidoximate and glutarimidedioximate from Table 8 along with those of the $\mathrm{UO}_{2}{ }^{2+}$ complexes with carbonate, ${ }^{51}$ speciation diagrams can be determined to show the competition between the ligands and carbonate for the complexation of uranyl under seawater conditions $\left(\mathrm{C}_{\text {uranyl }}=3.3 \mu \mathrm{g} \mathrm{L}^{-1}, \mathrm{C}_{\text {carbonate }}=0.0023 \mathrm{M}, \mathrm{pH}=8.3\right)$. Figure 12 shows the speciation diagram for $\mathrm{AO}^{-}$in comparison with the speciation diagram for $\mathrm{IDO}^{2-}$ at two different concentrations of the ligands. 

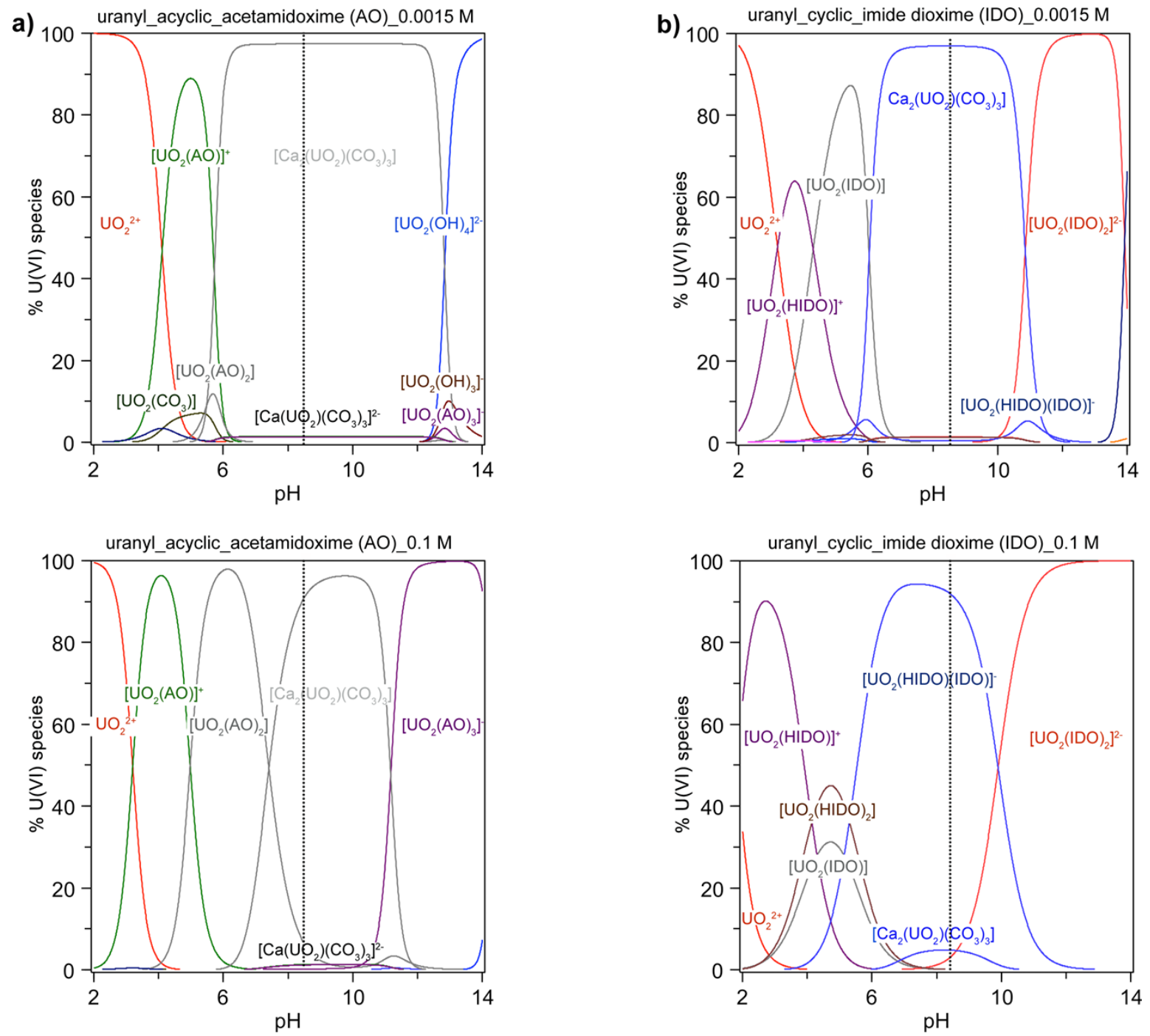

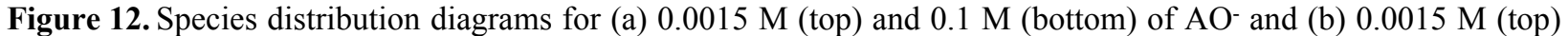
and $0.1 \mathrm{M}$ (bottom) of $\mathrm{IDO}^{2-}$ as a function of $\mathrm{pH}$. Concentration of ions used in simulation: $\mathrm{C}_{\text {uranyl }}=1.4 \mathrm{x}$ $10^{-8} \mathrm{M}, \mathrm{C}_{\text {calcium }}=0.0103 \mathrm{M}, \mathrm{C}_{\text {magnesium }}=0.053 \mathrm{M}, \mathrm{C}_{\text {carbonate }}=0.0023 \mathrm{M}$.

In the presence of $0.0015 \mathrm{M}$ acetamidoxime (Figure 12a, top), nearly all $\mathrm{UO}_{2}{ }^{2+}$ is complexed in the form of $\left[\mathrm{Ca}_{2}\left(\mathrm{UO}_{2}\right)\left(\mathrm{CO}_{3}\right)_{3}\right]$ at $\mathrm{pH} 8.3\left(95 \%\left[\mathrm{Ca}_{2}\left(\mathrm{UO}_{2}\right)\left(\mathrm{CO}_{3}\right)_{3}\right], 3 \%\left[\mathrm{Ca}\left(\mathrm{UO}_{2}\right)\left(\mathrm{CO}_{3}\right)_{3}\right]^{2-}\right.$, and $\left.2 \%\left[\mathrm{Mg}\left(\mathrm{UO}_{2}\right)\left(\mathrm{CO}_{3}\right)_{3}\right]^{2-}\right)$. Only when $\mathrm{pH}$ is above 12, acetamidoxime (HAO) starts to compete for complexing uranyl. In the presence of $0.1 \mathrm{M}$ acetamidoxime (Figure 12a, bottom), about $60 \% \mathrm{UO}_{2}{ }^{2+}$ is still complexed by the carbonate complex at pH $8.3\left(55 \%\left[\mathrm{Ca}_{2}\left(\mathrm{UO}_{2}\right)\left(\mathrm{CO}_{3}\right)_{3}\right], 3 \%\left[\mathrm{Ca}\left(\mathrm{UO}_{2}\right)\left(\mathrm{CO}_{3}\right)_{3}\right]^{2-}\right.$, and $\left.\left[\mathrm{Mg}\left(\mathrm{UO}_{2}\right)\left(\mathrm{CO}_{3}\right)_{3}\right]^{2-}\right)$. Only about $12 \% \mathrm{UO}_{2}{ }^{2+}$ is complexed by acetamidoxime in the form of $\left[\mathrm{UO}_{2}(\mathrm{AO})_{2}\right](10 \%)$ and $\left[\mathrm{UO}_{2}(\mathrm{AO})_{3}\right]^{-}(2 \%)$.

In contrast, even in the presence of the low concentration of glutarimidedioxime $(0.0015 \mathrm{M}), \sim 4 \%$ of $\mathrm{UO}_{2}{ }^{2+}$ is complexed by this ligand at $\mathrm{pH} 8.3$ (Figure 12b, top). Increasing the concentration of glutarimidedioxime $\left(\mathrm{H}_{2} \mathrm{IDO}\right)$ to $0.1 \mathrm{M}$ results in the formation of $\left[\mathrm{UO}_{2}(\mathrm{HIDO})(\mathrm{IDO})\right]^{-}$, which is the dominant species $(>90 \%)$ and only minor amounts of $\mathrm{UO}_{2}{ }^{2+}$ are present in the ternary $\left[\mathrm{Ca}_{2}\left(\mathrm{UO}_{2}\right)\left(\mathrm{CO}_{3}\right)_{3}\right]$ complex at $\mathrm{pH} 8.3$ (Figure $12 \mathrm{~b}$, bottom). This means that, though acetamidoximate $\left(\mathrm{AO}^{-}\right)$and glutarimidedioximate (IDO ${ }^{2-}$ ) form $\mathrm{UO}_{2}{ }^{2+}$ complexes with comparable binding strengths (Table 8), the former ( $\mathrm{AO}^{-}$) is a weaker competing ligand with carbonate than the latter $\left(\mathrm{IDO}^{2-}\right)$ for complexing uranyl at seawater $\mathrm{pH}$. The reason for the weaker competing ability of $\mathrm{AO}^{-}$with carbonate at $\mathrm{pH} 8.3 \mathrm{can}$ be explained by the fact that $\mathrm{AO}^{-}$has higher 
tendency for protonation (higher overall $\mathrm{pK}_{\mathrm{a}}$ values) than $\mathrm{IDO}^{2-}$. At $\mathrm{pH}$ higher than 8.3 when more acetamidoxime is deprotonated, the ability of $\mathrm{AO}^{-}$to compete with carbonate for complexing $\mathrm{UO}_{2}{ }^{2+}$ is expected to be stronger. In fact, the speciation diagrams in Figure $12 \mathrm{a}$ confirm that nearly $100 \% \mathrm{UO}_{2}{ }^{2+}$ would be complexed by $\mathrm{AO}^{-}$at $\mathrm{pH} 12$ when $\mathrm{C}_{\text {acetamidoxime }}=0.1 \mathrm{M}$.

Based on personal communications with our experimental collaborators, Dr. Rao (Lawrence Berkley National Laboratory) and Prof. Hancock (University of North Carolina Wilmington), measuring formation constants and other thermodynamic parameters for amidoxime/vanadium systems is a difficult task. For instance, although the crystal structures of rare non-oxido vanadium complexes with two cyclic imide dioxime ligands have been obtained, ${ }^{76}$ there were no reports on the stability constant $(\log \beta)$ values of the corresponding complexes. In addition, our experimental colleagues failed to determine $\log \beta$ for the vanadate $\left(\mathrm{VO}_{2}{ }^{+}\right)$complexes with simple acyclic acetamidoxime and $\mathrm{N}, \mathrm{N}$-dimethylbenzamidoxime ligands using fluorescence and absorbance techniques. Challenges of this nature emphasize the utility and value of our computational protocols for predicting $\log \beta$ values of $\mathrm{VO}_{2}{ }^{+}$, as experimental parameters are not required. The calculated stability constant values for the $\mathrm{VO}_{2}{ }^{+} / \mathrm{AO}^{-}$and $\mathrm{VO}_{2}{ }^{+} / \mathrm{IDO}^{2-}$ complexes, along with experimental $\log \beta$ for the formation of vanadate species are summarized in Table 9 .

Table 9. Equilibrium constants for the $\mathrm{VO}_{2}{ }^{+} / \mathrm{AO}^{-}$and $\mathrm{VO}_{2}+/ \mathrm{IDO}^{2-}$ complexes, together with literature constants for the $\mathrm{V}(\mathrm{V})$ solution species, all at $25^{\circ} \mathrm{C}$ and zero ionic strength.

\begin{tabular}{|c|c|}
\hline aqueous species, reactions & $\log \beta$ \\
\hline $\mathrm{V}(\mathrm{V}) \mathrm{a}$ & \\
\hline $\mathrm{VO}_{4}^{3-}+\mathrm{H}^{+} \mathrm{HVO}_{4}^{2-}$ & $14.3^{\mathrm{a}}$ \\
\hline $\mathrm{VO}_{4}^{3-}+2 \mathrm{H}^{+} \mathrm{H}_{2} \mathrm{VO}_{4}^{-}$ & $22.9^{a}$ \\
\hline $\mathrm{VO}_{4}^{3-}+3 \mathrm{H}^{+} \mathrm{H}_{3} \mathrm{VO}_{4}$ & 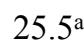 \\
\hline $\mathrm{VO}_{4}^{3-}+4 \mathrm{H}^{+}-\mathrm{VO}_{2}^{+}+2 \mathrm{H}_{2} \mathrm{O}$ & $30.2^{\mathrm{a}}$ \\
\hline $\begin{array}{l}\mathrm{VO}_{4}{ }^{3-}+4 \mathrm{H}^{+}+\mathrm{CO}_{3}{ }^{2-}\left[\mathrm{VO}_{2}\left(\mathrm{CO}_{3}\right)\right]^{-}+2 \mathrm{H}_{2} \mathrm{O} \\
\text { acetamidoximate }\left(\mathrm{AO}^{-}\right) \text {ligand: }\end{array}$ & $36.7^{\mathrm{a}}$ \\
\hline $\mathrm{VO}_{4}^{3-}+4 \mathrm{H}^{+}+\mathrm{AO}^{-}\left[\mathrm{VO}_{2}(\mathrm{AO})\right]+2 \mathrm{H}_{2} \mathrm{O}$ & $40.6^{\mathrm{b}}$ \\
\hline $\mathrm{VO}_{4}^{3-}+4 \mathrm{H}^{+}+2 \mathrm{AO}^{-}\left[\mathrm{VO}_{2}(\mathrm{AO})_{2}\right]^{-}+2 \mathrm{H}_{2} \mathrm{O}$ & 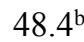 \\
\hline $\mathrm{VO}_{4}^{3-}+5 \mathrm{H}^{+}+2 \mathrm{AO}^{-}\left[\mathrm{VOOH}(\mathrm{AO})_{2}\right]+2 \mathrm{H}_{2} \mathrm{O}$ & $51.4^{\mathrm{b}}$ \\
\hline $6 \mathrm{H}^{+}+3 \mathrm{AO}^{-}\left[\mathrm{V}(\mathrm{AO})\left(\mathrm{AO}_{-} \mathrm{H}\right)_{2}\right]+4 \mathrm{H}_{2} \mathrm{O}$ & 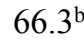 \\
\hline $\begin{array}{l}\mathrm{VO}_{4}{ }^{3-}+8 \mathrm{H}^{+}+3 \mathrm{AO}^{-}\left[\mathrm{V}(\mathrm{AO})_{3}\right]^{2+}+4 \mathrm{H}_{2} \mathrm{O} \\
\text { glutarimidedioximate }\left(\mathrm{IDO}^{2-}\right) \text { ligand: }\end{array}$ & $62.4^{\mathrm{b}}$ \\
\hline $\mathrm{VO}_{4}^{3-}+4 \mathrm{H}^{+}+\mathrm{IDO}^{2-}\left[\mathrm{VO}_{2}(\mathrm{IDO})\right]^{-}+2 \mathrm{H}_{2} \mathrm{O}$ & 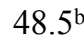 \\
\hline $\mathrm{VO}_{4}^{3-}+5 \mathrm{H}^{+}+\mathrm{IDO}^{2-}\left[\mathrm{VO}_{2}(\mathrm{HIDO})\right]+2 \mathrm{H}_{2} \mathrm{O}$ & $51.9^{\mathrm{b}}$ \\
\hline $\mathrm{VO}_{4}^{3-}+6 \mathrm{H}^{+}+2 \mathrm{IDO}^{2-}\left[\mathrm{V}\left(\mathrm{IDO} \_\mathrm{H}\right)_{2}\right]^{-}+4 \mathrm{H}_{2} \mathrm{O}$ & $76.4^{\mathrm{b}}$ \\
\hline $\mathrm{VO}_{4}^{3-}+7 \mathrm{H}^{+}+2 \mathrm{IDO}^{2-}[\mathrm{V}(\mathrm{IDO})(\mathrm{IDO} \mathrm{H})]+4 \mathrm{H}_{2} \mathrm{O}$ & 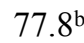 \\
\hline $\mathrm{VO}_{4}^{3-}+8 \mathrm{H}^{+}+2 \mathrm{IDO}^{2-}\left[\mathrm{V}(\mathrm{IDO})_{2}\right]^{+}+\overline{4} \mathrm{H}_{2} \mathrm{O}$ & 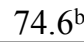 \\
\hline
\end{tabular}

${ }^{a}$ Taken from ref.44 and corrected to zero ionic strength with the Davies equation. ${ }^{57}$

${ }^{b}$ Predicted from correlations shown in Figure 5.

The complexation free energy, $\Delta G_{\mathrm{aq}}\left(\Delta G_{\mathrm{aq}}=\Delta G_{\mathrm{aq} 3}+2 G_{\mathrm{aq} 2}+\Delta G_{\mathrm{aq} 1}\right)$, for the formation of the non-oxido $\left[\mathrm{V}\left(\mathrm{IDO} \_\mathrm{H}\right)_{2}\right]^{-}$complex was found by a combination of the following reactions:

$$
\begin{aligned}
& \Delta G_{\mathrm{aq} 1}: \mathrm{H}_{2} \mathrm{VO}_{4}^{-}+2 \mathrm{H}^{+}-\mathrm{VO}_{2}^{+}+2 \mathrm{H}_{2} \mathrm{O} \\
& \Delta G_{\mathrm{aq} 2}: \mathrm{VO}_{2}^{+}+\mathrm{IDO}^{2-}\left[\mathrm{VO}_{2}(\mathrm{IDO})\right]^{-} \\
& \Delta G_{\mathrm{aq} 3}:\left[\mathrm{VO}_{2}(\mathrm{IDO})\right]^{-}+\left[\mathrm{VO}_{2}(\mathrm{IDO})\right]^{-}\left[\mathrm{V}\left(\mathrm{IDO} \mathrm{H}_{2}\right]^{-}+\mathrm{H}_{2} \mathrm{VO}_{4}^{-}\right.
\end{aligned}
$$

where the free energy, $\Delta G_{\text {aq } 3}$, was determined using high-level single-point CCSD(T)/SSC/aug-cc-pvDZ calculations. Following the same analysis, the equilibrium constants $(\log \beta)$ of the subsequent protonation of the [V(IDO_H $\left.)_{2}\right]^{-}$complex could be estimated to be 77.8 and 74.6 for the formation of [V(IDO)(IDO_H)] and $\left[\mathrm{V}(\mathrm{IDO})_{2}\right]^{+}$, respectively (Table 9 ). 
Similarly, we assessed $\log \beta$ for the formation of possible analogous non-oxido $3: 1$ acyclic acetamidoxime: $\mathrm{VO}_{2}{ }^{+}$complexes. The stability constant of the $\left[\mathrm{V}(\mathrm{AO})_{3}\right]^{2+}$ complex was calculated to be 62.4. However, first-principles molecular dynamic (MD) simulations of $\left[\mathrm{V}(\mathrm{AO})_{3}\right]^{2+}$ in a periodic cubic box, containing 62 water molecules and 2 hydroxide ions, showed that $\left[\mathrm{V}(\mathrm{AO})_{3}\right]^{2+}$ can undergo further deprotonation leading to the neutral $\left[\mathrm{V}(\mathrm{AO})\left(\mathrm{AO}_{-} \mathrm{H}\right)_{2}\right]$ complex with a slightly higher $\log \beta$ value of 66.3 (Table 9). Using the experimental and predicted stability constants from Table 9 , the speciation diagrams at different concentrations of the acyclic acetamidoximate $\left(\mathrm{AO}^{-}\right)$and cyclic imide-dioximate (IDO ${ }^{2-}$ ) ligands have been generated (Figure 13).
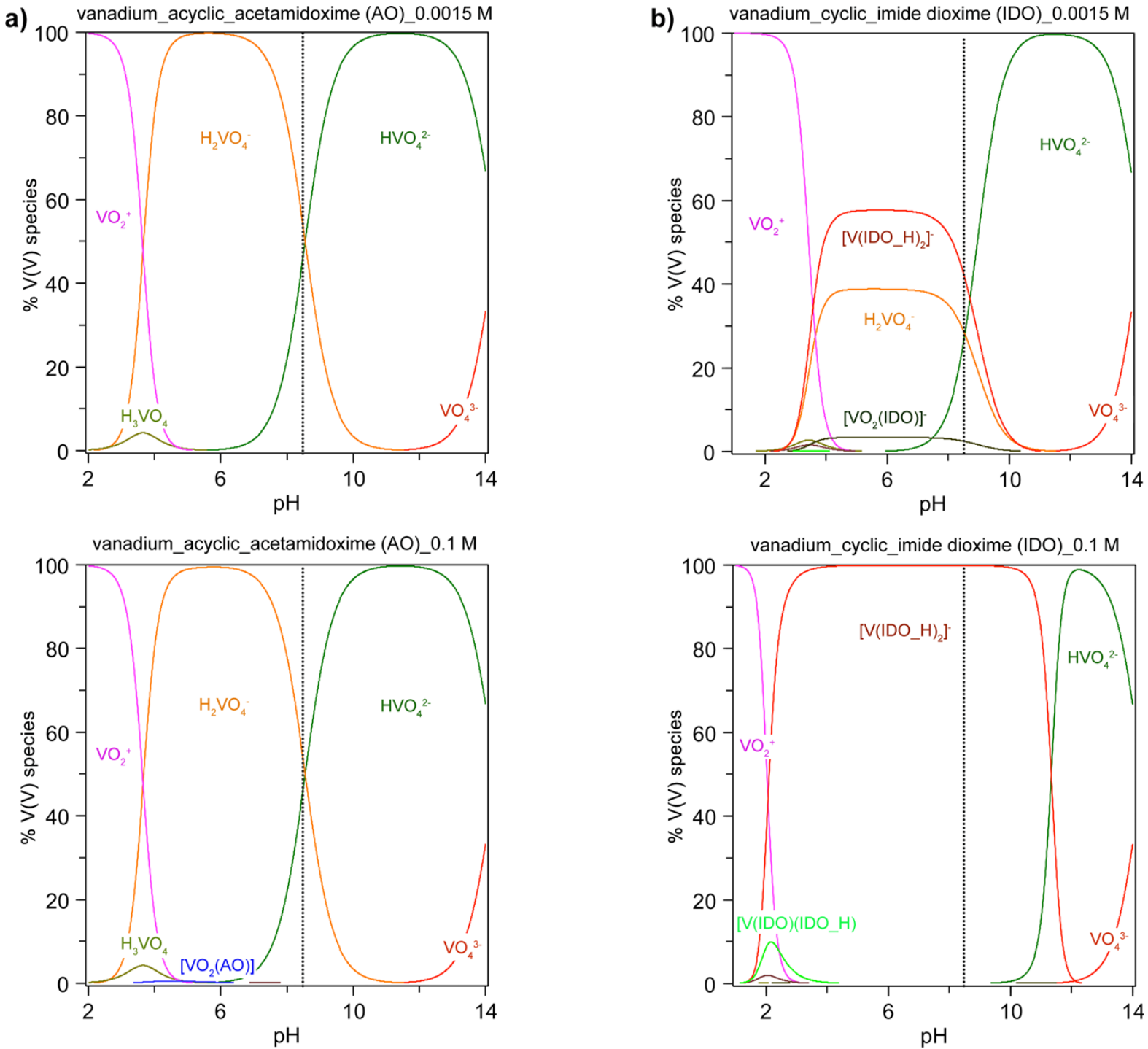

Figure 13. Species distribution diagrams for (a) $0.0015 \mathrm{M}$ (top) and $0.1 \mathrm{M}$ (bottom) of $\mathrm{AO}^{-}$and (b) $0.0015 \mathrm{M}$ (top) and $0.1 \mathrm{M}$ (bottom) of $\mathrm{IDO}^{2-}$ as a function of $\mathrm{pH}$. Concentration of ions used in simulation: $\mathrm{C}_{\mathrm{vanadium}}=3.6$ $\mathrm{x} 10^{-8} \mathrm{M}, \mathrm{C}_{\text {carbonate }}=0.0023 \mathrm{M}$.

As one may see in Figure 13, even in the presence of $0.0015 \mathrm{M} \mathrm{IDO}^{2-}$ (low concentration), $\mathrm{VO}_{2}{ }^{+}$is $(\sim 60 \%)$ complexed by the cyclic imide-dioxime ligand in the $\mathrm{pH}$ range $4-8.5$ (Figure 13b, top), while acyclic acetamidoximate $\left(\mathrm{AO}^{-}\right)$forms no complexes with $\mathrm{VO}_{2}{ }^{+}$(Figure 13a, top) due to being suppressed by the formation of the very stable $\mathrm{H}_{2} \mathrm{VO}_{4}{ }^{-}$anion. Increasing $\mathrm{AO}^{-}$concentration to $0.1 \mathrm{M}$ made little difference to 
the species distribution diagram, showing only a small fraction of the $\left[\mathrm{VO}_{2}(\mathrm{AO})\right]$ and $\left[\mathrm{VO}_{2}(\mathrm{AO})_{2}\right]^{-}$ complexes at the $\mathrm{pH}<8$ (Figure 13a, bottom). Hence, these results can successfully rationalize the experimental difficulties in determining the corresponding $\log \beta$ for this system. Contrary to the acyclic acetamidoxime functional group, in the presence of $0.1 \mathrm{M} \mathrm{IDO}^{2-}, 100 \%$ of $\mathrm{VO}_{2}{ }^{+}$is complexed (Figure $13 \mathrm{~b}$, bottom), indicating that the cyclic imide dioxime moiety should be avoided or minimized during the synthesis of amidoxime-based sorbent materials.

\subsubsection{Conclusions on Predicting Selectivity for Uranium vs. Vanadium}

The molecular design of novel chelating agents within a polymer fiber that possess high binding affinity and selectivity toward uranyl $v s$. vanadium species plays an important role in increasing sorption capacity of existing adsorbents. A key step in predicting ligand selectivity and efficiency at sequestering uranium is the ability to accurately predict the $\log K_{1}$ values for the uranyl and major competing $\mathrm{VO}^{2+}$ and $\mathrm{VO}_{2}{ }^{+}$ions. In this report, we have presented computational protocols, developed for $\mathrm{UO}_{2}{ }^{2+}, \mathrm{VO}^{2+}$ and $\mathrm{VO}_{2}{ }^{+}$complexes, that yield good accuracy (root-mean-square error $<1.34\left(\mathrm{UO}_{2}{ }^{2+}\right)$ and $<0.85\left(\mathrm{VO}^{2+}\right.$ and $\left.\mathrm{VO}_{2}{ }^{+}\right) \log$ units) by employing linear least-squares fitting of the calculated $\log K_{l}$ values to the experimental data available in the literature. Therefore, this work provides the essential foundation for computational screening of existing - or even yet unsynthesized - ligands with higher selectivity for uranium over vanadium. This is particularly significant when considering whether to make an otherwise highly attractive ligand that may be synthetically challenging. If such a ligand is predicted by our calculations to achieve the desired uranium versus vanadium selectivity, this substantially reduces the risk of taking on such synthetic challenges. Moreover, the elimination of ligands that are unlikely to show a good uranyl binding affinity can release resources to focus on more promising $\mathrm{UO}_{2}{ }^{2+}$ - selective ligands.

These newly developed computational protocols were subsequently used to assess the binding strengths and selectivity of aliphatic dicarboxylate ligands that can be present in the actual poly(acrylamidoxime) adsorbents. It was found that simple dicarboxylic functional groups possess low binding affinity and selectivity for uranyl because their backbones present architectures that are poorly organized for the $\mathrm{UO}_{2}{ }^{2+}$ complexation. These results can successfully rationalize the experimentally observed loss in selectivity of amidoxime-based fibers as the number of adsorption/elution cycles increases leading to the conversion of a significant amount of amidoxime to carboxylates. Moreover, the obtained data enabled us to propose the utilization of the ligand design principles based on structural preorganization to achieve a dramatic enhancement of carboxylates in $\mathrm{UO}_{2}{ }^{2+}$ ion binding affinity and selectivity. This concept was exemplified through the investigation of the complexes of the $\mathrm{UO}_{2}{ }^{2+}, \mathrm{VO}_{2}{ }^{+}$, and $\mathrm{VO}^{2+}$ ions with the highly preorganized ligand PDA (1,10-phenanthroline-2,9-dicarboxylic acid) by a combination of quantum chemical calculations, along with fluorescence and absorbance techniques. Due to its high chemical stability and selectivity for uranyl, PDA is a very promising candidate for the development of novel adsorbent materials for the selective extraction of uranium from seawater.

In addition, the aforementioned computational protocols were used to elucidate the main factors influencing the selectivity of the current generation of amidoxime-derived sorbents. In such amidoxime-based sorbents that are prepared by the current radiation-induced grafting process, various configurations of the functional groups could exist, including those represented by the open-chain amidoximate $\left(\mathrm{AO}^{-}\right)$and cyclic imide dioximate $\left(\mathrm{IDO}^{2-}\right)$. As follows from our results, the cyclic imide dioxime is the more preferable configuration for sequestration of uranium from seawater than the acyclic amidoxime. However, at the same time IDO ${ }^{2-}$ shows stronger binding affinity and higher selectivity for $\mathrm{VO}_{2}{ }^{+}$over $\mathrm{UO}_{2}{ }^{2+}$ and is likely responsible for the higher sorption of vanadium ions in marine tests, while $\mathrm{AO}^{-}$does not appear to bind the $\mathrm{VO}_{2}{ }^{+}$ions at all under seawater conditions. Furthermore, as indicated by the generated speciation diagrams, vanadium forms complexes with cyclic imide dioximate over a large range of $\mathrm{pH}$ values, which may complicate efforts to strip vanadium from the fibers that are being developed to sequester uranium. Thus, 
selectivity of poly(acrylamidoxime) adsorbents toward $\mathrm{UO}_{2}{ }^{2+} v s . \mathrm{VO}_{2}{ }^{+}$could be improved by minimizing the formation of the cyclic imide dioximate.

Overall, extensive deployment of the presented computational approaches in $\mathrm{UO}_{2}{ }^{2+}$-selective ligand discovery is expected to lead to more rapid completion of difficult projects related to the extraction of uranium from seawater, with superior adsorbent materials as an end result. It should be noted, however, that the presented aqueous complexation studies could be considered as initial evaluations of the ligands ability for the selective recovery of uranium. When the corresponding functional groups are grafted on solid substrates, their effective concentration and ability of extracting $\mathrm{UO}_{2}{ }^{2+}$ from seawater could be different from those observed in the above investigations. Therefore, a more rigorous adsorption model that incorporates the predicted thermodynamic parameters of uranyl and vanadium complexation has been developed to describe the experimental data of uranium extraction from seawater in the presence of competing vanadium species.

\subsection{Adsorption Simulations}

\subsubsection{System Parameters}

The adsorption model requires specific information about the system we intend to simulate in order to run. Our goal is to simulate and predict the adsorption capacities of the ORNL AF1 (a copolymer of amidoxime and itaconic acid) adsorbent under the lab scale capacity studies that were conducted. Relevant parameters for this system are provided below in Table 10.

Table 10. Summary of the system parameters used in the adsorption model. These parameters are based solely on the experimental conditions of the ORNL capacity studies and the AF1 fiber properties.

\begin{tabular}{|lll|}
\hline Parameter & Value & Additional Information \\
& & \\
AF1 Specific Area $(A)$ & $45000 \mathrm{~m}^{2} / \mathrm{kg}$ & Approximate surface area per mass of AF1 adsorbent \\
AF1 Max Capacity $\left(L_{\max }\right)$ & $2.9 \mathrm{~mol} / \mathrm{kg}$ & $\approx 690 \mathrm{~g} \mathrm{U} / \mathrm{kg}$ theoretical maximum capacity \\
Mass of Fibers $\left(m_{a}\right)$ & $15.1 \mathrm{mg}$ & Mass of fibers used by ORNL in capacity studies \\
Volume of system $(V)$ & $0.75 \mathrm{~L}$ & Volume of reactors used by ORNL in capacity studies \\
Temperature $(T)$ & $20^{\circ} \mathrm{C}$ & Temperature used by ORNL in capacity studies \\
Total Carbonate & $2.23 \times 10^{-3} \mathrm{M}$ & $\approx 140 \mathrm{ppm}$ of sodium bicarbonate \\
Total Salt $(\mathrm{NaCl})$ & $0.43 \mathrm{M}$ & $\approx 25.2 \mathrm{~g}$ of NaCl \\
Total Uranium & $3.23 \times 10^{-5} \mathrm{M}$ & $\approx 7.65 \mathrm{ppm}$ of Uranium \\
Total Vanadium & $5.82 \times 10^{-5} \mathrm{M}$ & $\approx 2.96 \mathrm{ppm}$ of Vanadium \\
\hline
\end{tabular}

\subsubsection{Adsorption Reactions}

The adsorption reactions and binding constants input into the model come directly from the molecular modeling studies (Tables 8 and 9) with one minor modification. First, the ligands on the surface of the adsorbent, $[L \phi]$ in equation 5, are considered as charge neutral in the formulation of the adsorption model, but the binding strengths from Tables 8 and 9 are given in terms of reactions with deprotonated ligands. To correct this, we only need to combine the deprotonation reactions of the ligands (Table 11) with the complexation reactions of the metals (Tables 8 and 9).

Table 11. Deprotonation reactions of the IDO and AO ligands with corresponding pKa values at $25{ }^{\circ} \mathrm{C}$ and zero ionic strength. 


\begin{tabular}{|ll|}
\hline Deprotonation Reaction & $\mathrm{pKa}$ \\
& \\
$\mathrm{H}_{2} \mathrm{IDO} 2 \mathrm{H}^{+}+\mathrm{IDO}^{2-}$ & -23.84 \\
$\mathrm{HAO} \mathrm{H}^{+}+\mathrm{AO}^{-}$ & -13.21 \\
\hline
\end{tabular}

An example of the modifications applied to the metal complexation reactions is shown below:

$\begin{array}{llcc} & \mathrm{H}_{2} \mathrm{IDO} 2 \mathrm{H}^{+}+\mathrm{IDO}^{2-} & \log K & =-23.84 \\ (+) & \mathrm{VO}_{4}{ }^{3-}+4 \mathrm{H}^{+}+\mathrm{IDO}^{2-}\left[\mathrm{VO}_{2}(\mathrm{IDO})\right]^{-}+2 \mathrm{H}_{2} \mathrm{O} & \log \beta & =48.45 \\ (=) & \mathrm{VO}_{4}{ }^{3-}+2 \mathrm{H}^{+}+\mathrm{H}_{2} \mathrm{IDO}\left[\mathrm{VO}_{2}(\mathrm{IDO})\right]^{-}+2 \mathrm{H}_{2} \mathrm{O} & \log K+\log \beta & =24.61\end{array}$

Here, we add the deprotonation reaction for $\mathrm{H}_{2} \mathrm{IDO}$ with the complexation reaction between $\mathrm{VO}_{4}{ }^{3-}$ and $\mathrm{IDO}^{2-}$. The end result is the corrected adsorption reaction that will be input into the model with a binding constant that is formed from the known $\mathrm{pKa}$ value of the deprotonation of $\mathrm{H}_{2} \mathrm{IDO}$ with the calculated binding strength between metal and ligand from the molecular modeling studies. Table 12 provides a summary of all of these adsorption reactions formulated in this manner and used in the modeling.

Table 12. Adsorption reactions and binding constants utilized by the model. These reactions and constants came from the molecular modeling studies and were used to predict uranium and vanadium adsorption.

\begin{tabular}{|c|c|}
\hline Adsorption Reactions & $\log \beta$ \\
\hline \multicolumn{2}{|l|}{ U with $\mathrm{AO}$ ligand: } \\
\hline $\mathrm{UO}_{2}^{2+}+\mathrm{HAO}\left[\mathrm{UO}_{2}(\mathrm{AO})\right]^{+}+\mathrm{H}^{+}$ & 0.4 \\
\hline $\mathrm{UO}_{2}^{2+}+2 \mathrm{HAO}\left[\mathrm{UO}_{2}(\mathrm{AO})_{2}\right]+2 \mathrm{H}^{+}$ & -2.7 \\
\hline $\mathrm{UO}_{2}^{2+}+3 \mathrm{HAO}\left[\mathrm{UO}_{2}(\mathrm{AO})_{3}\right]^{-}+3 \mathrm{H}^{+}$ & -11.7 \\
\hline $\mathrm{UO}_{2}^{2+}+\mathrm{HAO}+\mathrm{CO}_{3}^{2-}\left[\mathrm{UO}_{2}(\mathrm{AO})\left(\mathrm{CO}_{3}\right)\right]^{-}+\mathrm{H}^{+}$ & 2.6 \\
\hline $\mathrm{UO}_{2}{ }^{2+}+2 \mathrm{HAO}+\mathrm{CO}_{3}{ }^{2-}\left[\mathrm{UO}_{2}(\mathrm{AO})_{2}\left(\mathrm{CO}_{3}\right)\right]^{2-}+2 \mathrm{H}^{+}$ & -0.9 \\
\hline \multicolumn{2}{|l|}{ U with IDO ligand: } \\
\hline $\mathrm{UO}_{2}^{2+}+\mathrm{H}_{2} \mathrm{IDO}\left[\mathrm{UO}_{2}(\mathrm{IDO})\right]+2 \mathrm{H}^{+}$ & -4.6 \\
\hline $\mathrm{UO}_{2}^{2+}+\mathrm{H}_{2} \mathrm{IDO}\left[\mathrm{UO}_{2}(\mathrm{HIDO})\right]^{+}+\mathrm{H}^{+}$ & -0.3 \\
\hline $\mathrm{UO}_{2}^{2+}+2 \mathrm{H}_{2} \mathrm{IDO}\left[\mathrm{UO}_{2}(\mathrm{IDO})_{2}\right]^{2-}+4 \mathrm{H}^{+}$ & -18.7 \\
\hline $\mathrm{UO}_{2}{ }^{2+}+2 \mathrm{H}_{2} \mathrm{IDO}\left[\mathrm{UO}_{2}(\mathrm{HIDO})(\mathrm{IDO})\right]^{-}+3 \mathrm{H}^{+}$ & -8.8 \\
\hline $\mathrm{UO}_{2}^{2+}+2 \mathrm{H}_{2} \mathrm{IDO}\left[\mathrm{UO}_{2}(\mathrm{HIDO})_{2}\right]+2 \mathrm{H}^{+}$ & -3.5 \\
\hline $\mathrm{UO}_{2}^{2+}+\mathrm{H}_{2} \mathrm{IDO}+\mathrm{CO}_{3}^{2-}\left[\mathrm{UO}_{2}(\mathrm{IDO})\left(\mathrm{CO}_{3}\right)\right]^{2-}+2 \mathrm{H}^{+}$ & 1.4 \\
\hline $\mathrm{UO}_{2}{ }^{2+}+\mathrm{H}_{2} \mathrm{IDO}+\mathrm{CO}_{3}^{2-}\left[\mathrm{UO}_{2}(\mathrm{HIDO})\left(\mathrm{CO}_{3}\right)\right]^{-}+\mathrm{H}^{+}$ & 5.4 \\
\hline \multicolumn{2}{|l|}{$\mathrm{V}$ with $\mathrm{AO}$ ligand: } \\
\hline$\overline{\mathrm{VO}_{4}{ }^{3-}+3 \mathrm{H}^{+}+\mathrm{HAO}}\left[\mathrm{VO}_{2}(\mathrm{AO})\right]+2 \mathrm{H}_{2} \mathrm{O}$ & 27.3 \\
\hline $\mathrm{VO}_{4}^{3-}+2 \mathrm{H}^{+}+2 \mathrm{HAO}\left[\mathrm{VO}_{2}(\mathrm{AO})_{2}\right]^{-}+2 \mathrm{H}_{2} \mathrm{O}$ & 21.9 \\
\hline $\mathrm{VO}_{4}^{3-}+3 \mathrm{H}^{+}+2 \mathrm{HAO}\left[\mathrm{VOOH}(\mathrm{AO})_{2}\right]+2 \mathrm{H}_{2} \mathrm{O}$ & 24.9 \\
\hline $\mathrm{VO}_{4}^{3-}+3 \mathrm{H}^{+}+3 \mathrm{HAO}\left[\mathrm{V}(\mathrm{AO})(\mathrm{AO} \mathrm{H})_{2}\right]+4 \mathrm{H}_{2} \mathrm{O}$ & 26.6 \\
\hline $\mathrm{VO}_{4}^{3-}+5 \mathrm{H}^{+}+3 \mathrm{HAO}\left[\mathrm{V}(\mathrm{AO})_{3}\right]^{2+}+4 \mathrm{H}_{2} \mathrm{O}$ & 22.7 \\
\hline \multicolumn{2}{|l|}{ V with IDO ligand: } \\
\hline$\overline{\mathrm{VO}_{4}{ }^{3-}+2 \mathrm{H}^{+}+\mathrm{H}_{2} \mathrm{IDO}}\left[\mathrm{VO}_{2}(\mathrm{IDO})\right]^{-}+2 \mathrm{H}_{2} \mathrm{O}$ & 24.6 \\
\hline $\mathrm{VO}_{4}^{3-}+3 \mathrm{H}^{+}+\mathrm{H}_{2} \mathrm{IDO}\left[\mathrm{VO}_{2}(\mathrm{HIDO})\right]+2 \mathrm{H}_{2} \mathrm{O}$ & 28.1 \\
\hline $\mathrm{VO}_{4}^{3-}+2 \mathrm{H}^{+}+2 \mathrm{H}_{2} \mathrm{IDO}\left[\mathrm{V}(\mathrm{IDO}-\mathrm{H})_{2}\right]^{-}+4 \mathrm{H}_{2} \mathrm{O}$ & 28.7 \\
\hline $\mathrm{VO}_{4}^{3-}+3 \mathrm{H}^{+}+2 \mathrm{H}_{2} \mathrm{IDO}[\mathrm{V}(\mathrm{IDO})(\mathrm{IDO} \mathrm{H})]+4 \mathrm{H}_{2} \mathrm{O}$ & 30.1 \\
\hline $\mathrm{VO}_{4}{ }^{3-}+4 \mathrm{H}^{+}+2 \mathrm{H}_{2} \mathrm{IDO}\left[\mathrm{V}(\mathrm{IDO})_{2}\right]^{+}+\overline{4} \mathrm{H}_{2} \mathrm{O}$ & 26.9 \\
\hline
\end{tabular}

\subsubsection{Uranium Uptake Predictions}


Uranium adsorption for ORNL lab scale capacity studies were simulated using the adsorption model described in section 2.2 (Adsorption Modeling) and the surface reactions from Table 12. In each simulation case, it was assumed that the fiber adsorbents contained either the AO or IDO ligands as the reactive sites, with a ligand molar concentration of $2.9 \mathrm{~mol} / \mathrm{kg}$ (see Table 10). The simulation conditions for each case was the same and the notable parameters used in the model are summarized in Tables 10 and 12.

Results for the simulation of adsorption using the AO ligand are provided below in Figure 14. Figure 14b shows that the neutral $\mathrm{UO}_{2}(\mathrm{AO})_{2}$ is the dominant adsorbed uranium species across the range of $\mathrm{pH}$ from 1 to 12 . Only at higher $\mathrm{pH}$ is another species $\left(\mathrm{UO}_{2}(\mathrm{AO})_{3}{ }^{-}\right)$contributing to the adsorption of uranium. This contrasts somewhat with the aqueous speciation diagrams in Figure 12a (bottom), which shows that several charged metal-ligand complexes are dominant at different $\mathrm{pH}$ ranges. In the adsorption simulation, the surface charge balance (equations 8 -10) will typically favor adsorbed species that are charge neutral, which is why the $\mathrm{UO}_{2}(\mathrm{AO})_{2}$ species is dominant in this system. Using this adsorption model, the prediction of the ORNL capacity data shows very good agreement (Figure 14a), especially near the more neutral $\mathrm{pH}$ ranges.
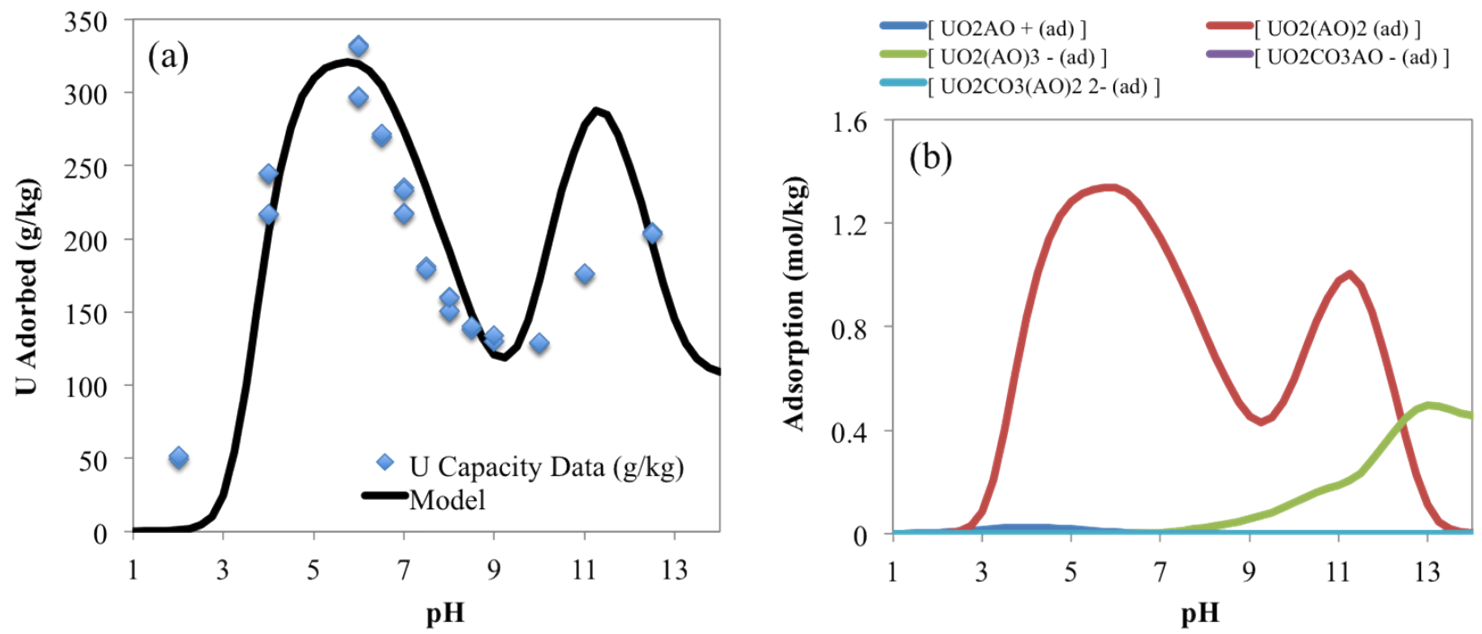

Figure 14. Uranium adsorption simulation results for the AO ligand compared to the ORNL capacity data (a) and the distribution of each surface species to the total amount of uranium adsorbed (b).

For uranium adsorption by the IDO ligand, the simulation results (Figure 15a) were more accurate between pH 5 and 9 compared to the AO ligand simulation (Figure 14a), but were worse outside of that range. Additionally, the IDO simulations showed that there were two primary adsorbing uranium species (Figure $15 \mathrm{~b}$ ), as opposed to the one dominant species predicted for the AO ligand (Figure 14b). The neutral $\mathrm{UO}_{2}(\mathrm{HIDO})_{2}$ is shown to be the primary surface species between $\mathrm{pH} 3$ and 8 , while the negatively charged $\mathrm{UO}_{2}$ (HIDO)IDO- takes over as the main adsorbed species from $\mathrm{pH} 8$ to 14 . This is also different compared to the aqueous speciation results from Figure $12 \mathrm{~b}$ (bottom), which shows $\mathrm{UO}_{2}$ (HIDO)IDO- clearly dominant between $\mathrm{pH} 6$ and 10. This difference is likely caused by the charge neutralization requirement of the surface (as mentioned before), which will favor uncharged adsorbed species in the more neutral $\mathrm{pH}$ ranges. 

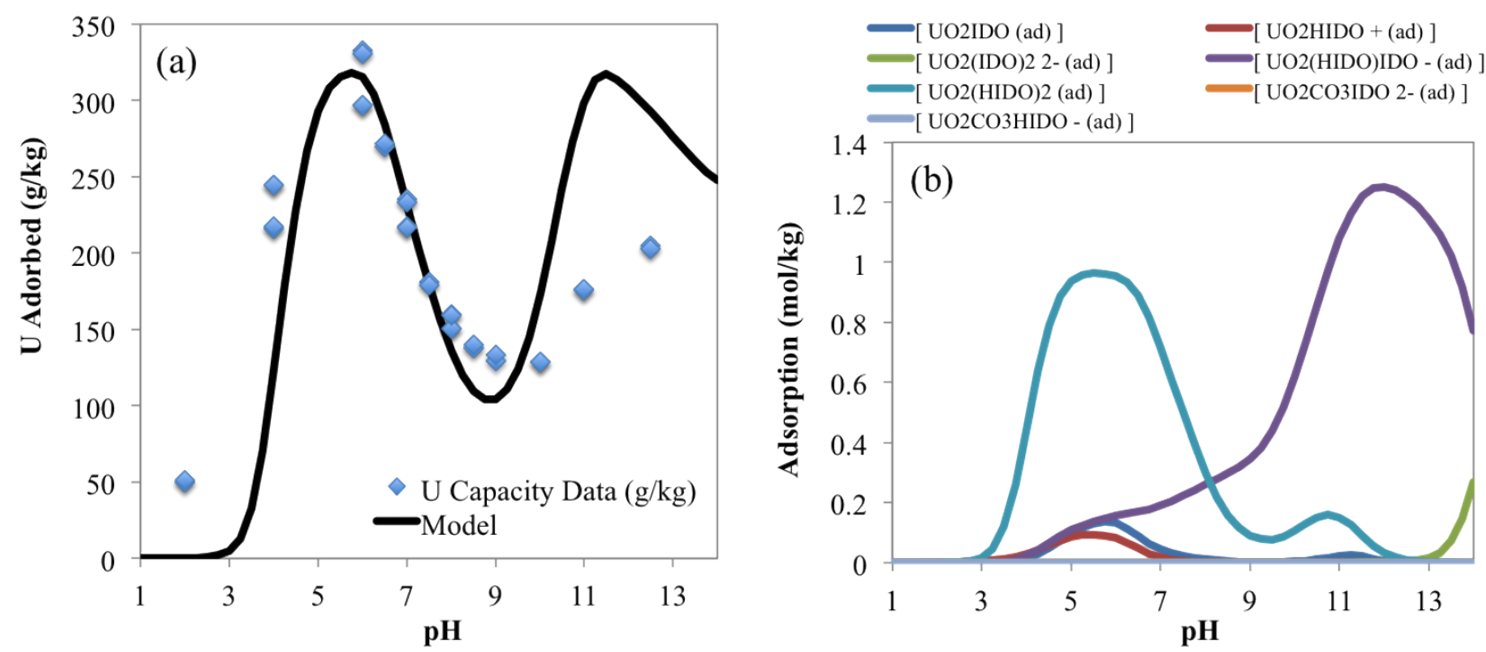

Figure 15. Uranium adsorption simulation results for the IDO ligand compared to the ORNL capacity data (a) and the distribution of each surface species to the total amount of uranium adsorbed (b).

\subsubsection{Vanadium Uptake Predictions}

While the uranium adsorption modeling was very successful, initial vanadium predictions based on the ORNL capacity studies did not describe the data well (Figure 16). Figure 16a shows that the model significantly underestimates the total adsorption of the vanadium on the AF1 fibers when considering the IDO ligand. We did not show the AO ligand results because the model showed no adsorption with the AO ligand, which was a conclusion mirrored by the molecular modeling studies (Figure 13a). However, the molecular modeling studies also suggest that there should have been significant vanadium uptake by IDO in the more neutral $\mathrm{pH}$ ranges (Figure 13b). The adsorption model does agree that the primary adsorbing species is the negatively charge $\mathrm{V}\left(\mathrm{IDO} \_\mathrm{H}\right)_{2}{ }^{-}$(Figure $16 \mathrm{~b}$ ), but the range and quantity of this species does not accurately reflect the trends seen in the ORNL data (Figure 16a).
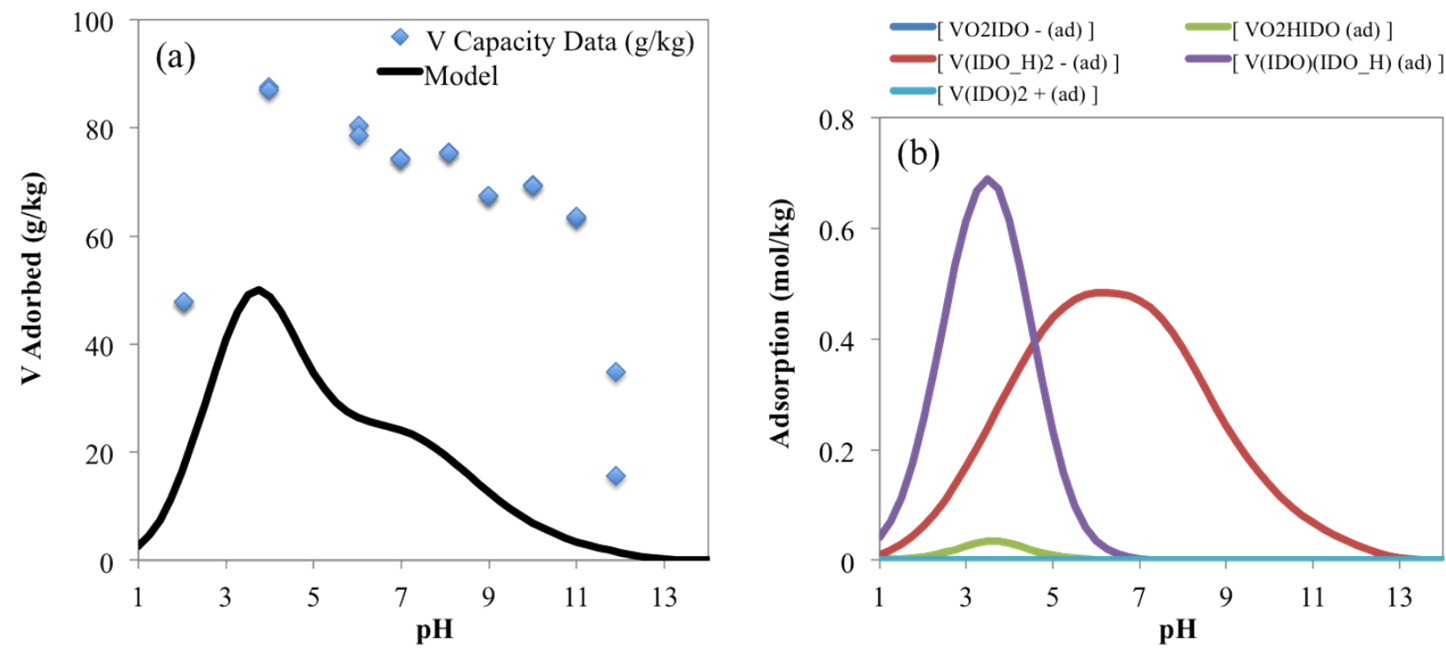

Figure 16. Vanadium adsorption simulation results for the IDO ligand compared to the ORNL capacity data (a) and the distribution of each surface species to the total amount of uranium adsorbed (b).

Recall that the primary differences observed for uranium adsorption between the adsorption speciation (Figure 14 and 15) and the aqueous speciation (Figure 12) were attributed to the effect of surface charging included in the adsorption model (equations $8-10$ ). Surface species that were neutrally charged were 
favored in the adsorption model and led to higher adsorption capacities than their charged counterparts. Based on this observation, one could ascertain that if the primary adsorbing vanadium species were charge neutral, then it would result in a higher adsorption capacity for vanadium. However, the charge neutral vanadium species considered as part of the modeling ( $\mathrm{VO}_{2} \mathrm{HIDO}$ and $\mathrm{V}$ (IDO)(IDO_H)) appear only in a narrow $\mathrm{pH}$ range centered around a $\mathrm{pH}$ of 3 (Figures $13 \mathrm{~b}$ and $16 \mathrm{~b}$ ). Therefore, there might be some other charge neutral species, or charge neutralizing effect, that is involved with vanadium adsorption.

To explore this idea of charge neutralization, consider the crystal structures of the vanadium/IDO complexes synthesized by Leggett et al. ${ }^{76}$ In their paper, Leggett and co-workers identified a 1:2 vanadium/IDO structure that was charge neutral via the addition/association of the complex with a sodium ion $\left(\mathrm{NaV}\left(\mathrm{IDO} \_\mathrm{H}\right)_{2}\right)$. They postulated that this crystal structure would complex in solution as V(IDO_H $)_{2}{ }^{-}$, but was also noted that in the crystal the $\mathrm{Na}^{+}$ion would act as a bridge to connect other $\mathrm{NaV}\left(\mathrm{IDO}{ }_{-}\right)_{2}$ complexes together. In adsorption, the IDO ligands are already in very close proximity to each other and the desire of the surface to maintain charge neutrality could feasibly bring $\mathrm{Na}^{+}$ions from solution to associate with the $\mathrm{V}\left(\mathrm{IDO} \_\mathrm{H}\right)_{2}{ }^{-}$species, especially considering the very high concentration of sodium in seawater and lab scale tests (Table 10).

In order to examine the effect of charge neutralization caused by $\mathrm{Na}^{+}$ions, we modified the original vanadium and IDO adsorption reactions (Table 12) to include the following reaction:

$$
\mathrm{VO}_{4}{ }^{3-}+2 \mathrm{H}^{+}+\mathrm{Na}^{+}+2 \mathrm{H}_{2} \mathrm{IDO}\left[\mathrm{NaV}\left(\mathrm{IDO}_{-} \mathrm{H}_{2}\right]+4 \mathrm{H}_{2} \mathrm{O} \quad: \quad \log \beta=29.2\right.
$$

The binding strength for this reaction was taken from the $\log \beta$ for the formation of the V(IDO_H $)_{2}^{-}$species $(\log \beta=28.7)$ modified by the concentration of the $\mathrm{Na}^{+}$ions in solution $\left(10^{29.2} \approx 10^{28.7} / 0.36\right)$. Results for the adsorption simulation including this charge neutralization reaction are shown in Figure 17. These results have significantly better agreement with the ORNL capacity data (Figure 17a) than the previous vanadium simulation result (Figure 16a). In addition, the adsorption speciation diagram (Figure 17b) and the aqueous speciation diagram (Figure 13b) qualitatively agree more closely with each other in terms of the relative amounts of each different vanadium/IDO complex and the $\mathrm{pH}$ ranges in which they occur. These results suggest that during adsorption the vanadium adsorbed to the fibers may attract $\mathrm{Na}^{+}$ions from solution in an effort to neutralize charge on the surface.
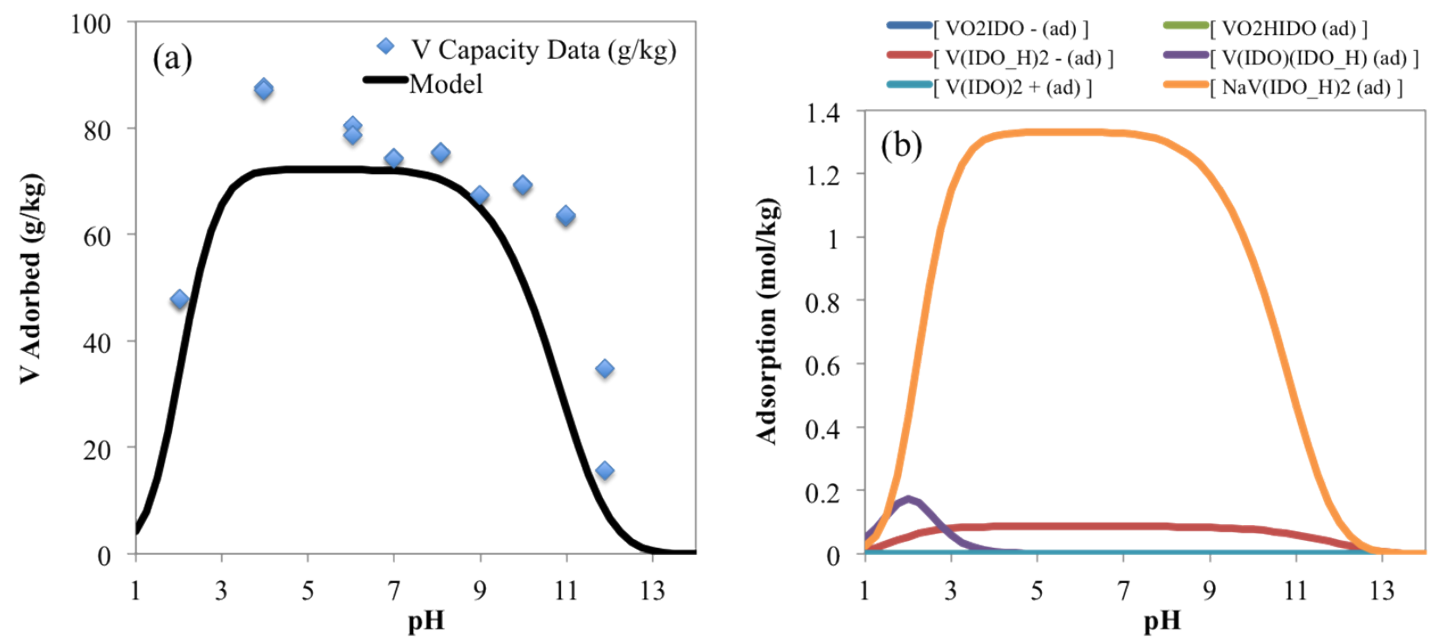

Figure 17. Vanadium adsorption simulation results for the IDO ligand, with $\mathrm{Na}^{+}$counter-ion charge neutralization, compared to the ORNL capacity data (a) and the distribution of each surface species to the total amount of uranium adsorbed (b).

\subsubsection{Conclusions on Adsorption Modeling}


Adsorption reactions are very different from aqueous reactions, thus must be treated differently mathematically when doing any kind of process modeling. Impacts of adsorption are felt by the aqueous phase by removing ions from solution and reducing the amount of aqueous metals available. The reactions of adsorption look similar to aqueous reactions, but involve their own site balance to account for the availability of ligands on the surface of the adsorbent. In addition, the binding strengths for each adsorption reaction become modulated as the surface accumulates charge through the addition and/or removal of ions. In general, the surface phase will try to maintain its own electroneutrality, thus reactions that result in neutral surface species will often be favored.

Molecular modeling studies provided a set of reactions and binding strengths associated with uranium and vanadium with acyclic (AO) and cyclic (IDO) amidoxime-based ligands. With little or no modification to these reactions and their binding strengths, we found that we were able to model the ORNL lab scale capacity experiments with reasonable accuracy. For the adsorption of uranium by AO and IDO ligands, the model worked exceptionally well for predicting the uranium capacity of the AF1 adsorbent between pH 5 and $\mathrm{pH} 9$, which is the most relevant range of $\mathrm{pH}$ for studying adsorption in real seawater. The adsorption model did not see any adsorption of vanadium with the AO ligand, which was also concluded by the molecular modeling studies. However, the adsorption model initially underestimated the capacity of vanadium with the IDO ligand.

Through investigation of the crystal structure of the 1:2 vanadium/IDO complex, we found that by including $\mathrm{a} \mathrm{Na}^{+}$ion into this structure, the adsorption model made much better predictions to the vanadium capacities. This is attributed to the charge neutralization effect that the sodium ions produce when in close association to the $\mathrm{V}\left(\mathrm{IDO} \_\mathrm{H}\right)_{2}{ }^{-}$species on the surface of the adsorbent. These results also indicate that the adsorption model is very sensitive to surface charging and charge neutralization, and will become very important when considering seawater adsorption modeling given the number of other counter-ions that are present $\left(\mathrm{Ca}^{2+}\right.$, $\mathrm{Mg}^{2+}$, etc.).

Overall, the culmination of molecular modeling studies and adsorption modeling techniques has shown significant promise with regards to ligand design and adsorbent performance prediction. We have demonstrated that the complexation reactions and binding strengths developed through molecular studies can yield the necessary parameters to predict the performance of a particular adsorbent when the appropriate structural parameters are also known (i.e., ligand surface density, specific surface area, mass, volume, etc.). From this progress, we now have a computational pathway to adsorbent fiber design, including the types of ligands to include and how much ligand should be on the surface versus the total available surface area of the fibers. However, there are still some improvements to be made to the modeling.

Currently, the adsorption model only considers one type of ligand to be a reactive site available to bind metals from solution. In reality, there are likely to by many different forms/types of ligands that will all bind in different ways. Therefore, we need to further develop the model to be capable of including any number of different types of ligands that may share the same surface space. Additionally, we have identified that surface charging caused by adsorption of ions has a large impact on the species found on the surface, as well as the total amount of a given metal that can adsorb to the fiber. Thus, we need to be mindful of the counter-ions in a given solution and how they may be co-adsorbed, or associated, with the adsorbing metals in an effort to neutralize the surface charge.

\section{Acknowledgment}


This work was sponsored by the Office of Nuclear Energy of the U.S. Department of Energy.

\section{References}

1. U.S. Nuclear Regulatory Commission. Final Generic Environmental Impact Statement on Uranium Milling; U.S. Nuclear Regulatory Commission; Washington, DC, 1980; NUREG-0706.

2. OCED, Uranium 2014: Resources, Production, and Demand, 2014.

3. R. V. Davies, J. Kennedy, R. W. McIlroy, R. Spence and K. M. Hill, Nature, 1964, 203, 1110.

4. D. L. Clark, D. E. Hobart and M. P. Neu, Chem. Rev., 1995, 95, 25.

5. J. D. Wilson, R. K. Webster, G. W. C. Milner, G. A. Barrett and A. A. Smales, Anal. Chim. Acta, 1960, 23, 505 .

6. I. Tabushi, Y. Kobuke and T. Nishiya, Nature, 1979, 280, 665.

7. A. C. Q. Ladeira and C. A. Morais, Minerals Eng., 2005, 18, 1337.

8. P. S. Kulkarni, S. Mukhopadhyay, M. P. Bellary and S. K. Ghosh, Hydrometallurgy, 2002, 64, 49.

9. R. S. S. Murthy and D. E. Ryan, Anal. Chem., 1983, 55, 682.

10. T. Takeda, K. Saito, K. Uezu, S. Furusaki, T. Sugo and J. Okamoto, Ind. Eng. Chem. Res., 1991, 30, 185.

11. M. Tamada, N. Seko, N. Kasai and T. Shimizu, Trans. At. Energy Soc. Japan, 2006, 5, 358.

12. I. Tabushi, Y. Kobuke and T. Nishiya, Nature, 1979, 280, 665.

13. M. J. Kanno, Nucl. Sci. Technol., 1984, 21, 1.

14. J. Kim, C. Tsouris, Y. Oyola, C. J. Janke, R. T. Mayes, S. Dai, G. Gill, L.-J. Kuo, J. Wood, K.-Y. Choe, E. Schneider and H. Lindner, Ind. Eng. Chem. Res., 2014, 53, 6076.

15. Fuel Cycle Technologies Annual Review Meeting Transactions Report, INL/EXT-14-33501, FCRDFCT-2015-000003, Idaho National Laboratory, Idaho Falls, Idaho 83415, 2015. http://www.inl.gov.

16. J. Kim, C. Tsouris, R. T. Mayes, Y. Oyola, T. Saito, C. J. Janke, S. Dai, E. Schneider and D. Sachde, Sep. Sci. Technol., 2013, 48, 367.

17. T. Suzuki, K. Saito, T. Sugo, H. Ogura and K. Oguma, Anal. Sci., 2000, 16, 429.

18. S. Vukovic, L. Watson, S. O. Kang, R. Custelcean and B. P. Hay, Inorg. Chem., 2012, 51, 3855.

19. G. Tian, S. J. Teat, Z. Zhang and L. Rao, Dalton Trans., 2012, 41, 11579.

20. S. Vukovic and B. P. Hay, Inorg. Chem., 2013, 52, 7805.

21. C. F. Xu, J. Su, X. Xu and J. Li, Sci. China: Chem., 2013, 56, 1525.

22. C. Z. Wang, J.-H. Lan, Q. Y. Wu, Q. Luo, Y. L. Zhao, X. K. Wang, Z. F. Chai and W. Q. Shi, Inorg. Chem., 2014, 53, 9466.

23. C. Priest, Z. Q. Tian and D. E. Jiang, Dalton Trans., 2016, 45, 9812-9819.

24. C. W. Abney, S. Liu and W. Lin, J. Phys. Chem. A, 2013, 117, 11558.

25. M. J. Frisch, G. W. Trucks, H. B. Schlegel, G. E. Scuseria, M. A. Robb, J. R. Cheeseman, G. Scalmani, V. Barone, B. Mennucci, G. A. Petersson, H. Nakatsuji, M. Caricato, X. Li, H. P. Hratchian, A. F. Izmaylov, J. Bloino, G. Zheng, J. L. Sonnenberg, M. Hada, M. Ehara, K. Toyota, R. Fukuda, J. Hasegawa, M. Ishida, T. Nakajima, Y. Honda, O. Kitao, H. Nakai, T. Vreven, J. A. Montgomery, Jr. , J. E. Peralta, F. Ogliaro, M. Bearpark, J. J. Heyd, E. Brothers, K. N. Kudin, V. N. Staroverov, R. Kobayashi, J. Normand, K. Raghavachari, A. Rendell, J. C. Burant, S. S. Iyengar, J. Tomasi, M. Cossi, N. Rega, M. J. Millam, M. Klene, J. E. Knox, J. B. Cross, V. Bakken, C. Adamo, J. Jaramillo, R. Gomperts, R. E. Stratmann, O. Yazyev, A. J. Austin, R. Cammi, C. Pomelli, J. W. Ochterski, R. L. Martin, K. Morokuma, V. G. Zakrzewski, G. A. Voth, P. Salvador, J. J. Dannenberg, S. Dapprich, A. D. Daniels, Ö. Farkas, J. B. 
Foresman, J. V. Ortiz, J. Cioslowski and D. J. Fox, Gaussian 09 Revision D.01, Wallingford, CT, Gaussian, Inc., 2009.

26. A. D. Becke, J. Chem. Phys., 1993, 98, 5648.

27. C. Lee, W. Yang and R. G. Parr, Phys. Rev. B, 1988, 37, 785.

28. Y. Zhao and D. G. Truhlar, Theor. Chem. Acc., 2008, 120, 215.

29. M. Dolg, H. Stoll, H. Preuss and R. M. Pitzer, J. Phys. Chem., 1993, 97, 5852.

30. R. F. Ribeiro, A. V. Marenich, C. J. Cramer and D. G. Truhlar, J. Phys. Chem. B, 2011, 115, 14556.

31. A. V. Marenich, C. J. Cramer and D. G. Truhlar, J. Phys. Chem. B, 2009, 113, 6378.

32. G. Kresse and J. Furthmüller, Comput. Mater. Sci., 1996, 6, 15-50.

33. G. Kresse and J. Furthmüller, Phys. Rev. B, 1996, 54, 11169-11186.

34. G. Kresse and J. Hafner, Phys. Rev. B, 1993, 47, 558-561.

35. P. E. Blöchl, Phys. Rev. B, 1994, 50, 17953-17979.

36. G. Kresse and D. Joubert, Phys. Rev. B, 1999, 59, 1758-1775.

37. J. P. Perdew, K. Burke and M. Ernzerhof, Phys. Rev. Lett., 1996, 77, 3865-3868.

38. J. P. Perdew, K. Burke and M. Ernzerhof, Phys. Rev. Lett., 1997, 78, 1396-1396.

39. C. J. Chandler, L. W. Deady and J. A. Reiss, J. Heterocyclic Chem. 1981, 18, 599.

40. E. J. Billo, EXCEL for Chemists. Wiley VCH: New York, 2001.

41. D. A. Knoll and D. E. Keyes, J. Comp. Phys., 2004, 193, 357-397.

42. Y. Saad, Iterative Methods for Sparse Linear Systems, $2^{\text {nd }}$ Ed., SIAM, Philadelphia, PA, 2003.

43. Y. Saad and M. H. Schultz, SIAM J. Sci. Stat. Comp., 1986, 7, 856-869.

44. M. M. Benjamin, Water Chemistry, Waveland Press, Inc., Illinois, 2010.

45. D. L. Parkhurst and C. A. J. Appelo, PHREEQC version 3-A computer program for speciation, U.S. Geological Survey Techniques and Methods, available at http://pubs.usgs.gov/tm/06/a43/, 2013.

46. W. D. Schecher and D. C. McAvoy, MINEQL+: A chemical equilibrium program for personal computers - User's manual, Environmental Research Software: Hallowell, ME, 2003.

47. S. Yiacoumi and C. Tien, Kinetics of Metal Ion Adsorption from Aqueous Solutions, Kluwer Academic Publishers, Boston, MA, 1995.

48. X. Sun, C. Xu, G. Tian and L. Rao, Dalton Trans., 2013, 42, 14621.

49. S. P. Kelley, P. S. Barber, P. H. Mullins and R. D. Rogers, Chem. Comm., 2014, 50, 12504.

50. C. J. Leggett, F. Endrizzi and L. Rao, Ind. Eng. Chem. Res., 2015, 55, 4257-4263.

51. (a) NIST Standard Reference Database 46. NIST Critically Selected Stability Constants of Metal Complexes Database, version 8.0; Data collected and selected by Smith, R. M., Martell, A. E.; US Department of Commerce, National Institute of Standards and Technology: Gaithersburg, MD, 2004. (b) The IUPAC Stability Constants Database; Academic Software: Yorks, UK, http://www. acadsoft.co.uk/scdbase/scdbase.htm.

52. R. Guillaumont, T. Fanghanel, J. Fuger, I. Grenthe, D. Palmer, M. Rand and V. Neck, Chemical Thermodynamics of Uranium, Neptunium, Plutonium, Americium and Technetium; NEA/OECD North Holland: Amsterdam, 2003.

53. G. Tian, S. J. Teat, Z. Zhang and L. Rao, Dalton Trans. 2012, 41, 11579-11586.

54. M. A. Lashley, N. Mehio, J. W. Nugent, E. Holguin, C.-L. Do-Thanh, V. S Bryantsev, S. Dai and R. D. Hancock, Polyhedron, 2016, 109, 81-91.

55. X. Sun, G. Tian, C. Xu, L. Rao, S. Vukovic, S. Kang and B. Hay, Dalton Trans. 2014, 43, 551- 557.

56. N. Mehio, A. S. Ivanov, N. J. Williams, R. T. Mayes, V. S. Bryantsev, R. D. Hancock and S. Dai, Dalton. Trans., 2016, 45, 9051-9064. 
57. C. W. Davies, Ion Association; Butterworths: Washington, DC, 1962.

58. (a) J. Neuefeind, L. Soderholm and S. Skanthakumar, J. Phys. Chem. A 2004, 109, 2733-2739. (b) L. Soderholm, S. Skanthakumar and J. Neuefeind, Anal. Bioanal. Chem. 2005, 383, 48-55.

59. (a) D. M. Chipman, F. Chen, J. Chem. Phys. 2006, 124144507. (b) B. Ginovska, D. M. Camaioni, M. Dupuis, C. A. Schwerdtfeger and Q. Gil, J. Phys. Chem. A 2008, 112, 10604-10613.

60. N. Mehio, J. C. Johnson, S. Dai and V. S. Bryantsev, Phys. Chem. Chem. Phys., 2015, 17, 31715.

61. N. Mehio, A. S. Ivanov, A. P. Ladshaw, S. Dai and V. S. Bryantsev, Ind. Eng. Res. Chem., 2015, 55, 4231-4240.

62. V. S. Bryantsev, M. S. Diallo and W. A. Goddard III, J. Phys. Chem. A, 2009, 113, 9559.

63. A. S. Ivanov, V. S. Bryantsev, Dalton Trans., 2016, 45, 10744.

64. S. Vukovic, B. P. Hay and V. S. Bryantsev, Inorg. Chem., 2015, 54, 3995.

65. T. Kawai, K. Saito, K. Sugita, T. Kawakami, J. Kanno, A. Katakai, N. Seko and T. Sugo, Rad. Phys. Chem. 2000, 59, 405.

66. S. Das, W.-P. Liao, M. Flicker Byers, C. Tsouris, C. J. Janke, R. T. Mayes, E. Schneider, L.-J. Kuo, J. R. Wood, G. A. Gill, G. A. and S. Dai, Ind. Eng. Res. Chem. 2016, 55, 4303.

67. S.-H. Choi, Y. C. Nho, Radiat. Phys. Chem. 2000, 57, 187.

68. C. Z. Wang, J.-H. Lan, Q. Y. Wu, Q. Luo, Y. L. Zhao, X. K. Wang, Z. F. Chai and W. Q. Shi, Inorg. Chem., 2014, 53, 9466.

69. D. L. Melton, D. G. VanDerveer and R. D. Hancock, Inorg. Chem., 2006, 45, 9306.

70. N. E. Dean, R. D. Hancock, C. L. Cahill and M. Frisch, Inorg. Chem., 2008, 47, 2000.

71. N. J. Williams, N. E. Dean, D. G. VanDerveer, R. C. Luckay and R. D. Hancock, Inorg. Chem., 2009, 48, 7853.

72. M. A. Lashley, A. S. Ivanov, V. S. Bryantsev, S. Dai, and R. D. Hancock. Inorg. Chem. (under revision). 73. I. Grenthe, J. Drozdzynski, T. Fujino, E. C. Buck, T. E. Albrecht-Schmitt and S. F. Wolf, The chemistry of the actinide and transactinide elements, 3rd ed., Morss, L. R., Edelstein, N. M., Fuger, J. (eds.). Springer: Netherlands, 2006, Vol. 1, pp. 599-601.

74. I. Grenthe, J. Fuger, R. J. M. Konings, R. J. Lemire, A. B. Muller, C. Nguyen-Trung, H. Wanner, Chemical Thermodynamics of Uranium, NEA/OECD, North Holland, 1992.

75. R. Guillamont, T. Fanghänel, J. Fuger, I. Grenthe, D. Palmer, M. Rand, V. Neck, Chemical Thermodynamics of Uranium, Neptunium, Plutonium, Americium, and Technetium, NEA/OECD, North Holland, 2003.

76. C. J. Leggett, B. F. Parker, S. J. Teat, Z. Zhang, P. D. Dau, W. W. Lukens, S. M. Peterson, A. J. P. Cardenas, M. G. Warner, J. K. Gibson, J. Arnold, L. Rao, Chem. Sci. 2016, 7, 2775-2786.

77. L. Astheimer, H.J. Schenk, E.G. Witte, and K. Schwochau, Development of sorbers for the recovery of uranium from seawater. Part 2. Sep. Sci. Technol.,1983, 18, 307-339.

78. S. Das, S. Brown, R. T. Mayes, C. J. Janke, C. Tsouris, L.-J. Kuo, G. Gill and S. Dai, Chem. Eng. J., 2016, 298, 125-135.

79. R. Chester and T. D. Jickells, Marine Geochemistry. $3^{\text {rd }}$ Edition, Wiley-Blackwell Publishing, New York, 2012.

80. F. Endrizzi, C. J. Leggett and L. Rao. Ind. Eng. Chem. Res., 2016, 55, 4249-4256. 